\title{
The Zebrafish Ortholog of TRPV1 Is Required for Heat-Induced Locomotion
}

\author{
Philia Gau, ${ }^{1,2 \star}$ Jason Poon, ${ }^{1 \star}$ Carmen Ufret-Vincenty, ${ }^{3}$ Corey D. Snelson, ${ }^{1}$ Sharona E. Gordon, ${ }^{2,3}$ David W. Raible, ${ }^{1,2}$ \\ and Ajay Dhaka ${ }^{1,2}$ \\ ${ }^{1}$ Department of Biological Structure, ${ }^{2}$ Neurobiology and Behavior Graduate Program, and ${ }^{3}$ Department of Physiology and Biophysics, University of \\ Washington, Seattle, Washington 98195
}

The ability to detect hot temperatures is critical to maintaining body temperature and avoiding injury in diverse animals from insects to mammals. Zebrafish embryos, when given a choice, actively avoid hot temperatures and display an increase in locomotion similar to that seen when they are exposed to noxious compounds such as mustard oil. Phylogenetic analysis suggests that the single zebrafish ortholog of TRPV1/2 may have arisen from an evolutionary precursor of the mammalian TRPV1 and TRPV2. As opposed to TRPV2, mammalian TRPV1 is essential for environmentally relevant heat sensation. In the present study, we provide evidence that the zebrafish TRPV1 ion channel is also required for the sensation of heat. Contrary to development in mammals, zebrafish TRPV1 ${ }^{+}$neurons arise during the first wave of somatosensory neuron development, suggesting a vital importance of thermal sensation in early larval survival. In vitro analysis showed that zebrafish TRPV1 acts as a molecular sensor of environmental heat $\left(\geq 25^{\circ} \mathrm{C}\right)$ that is distinctly lower than the sensitivity of the mammalian form $\left(\geq 42^{\circ} \mathrm{C}\right)$ but consistent with thresholds measured in behavioral assays. Using in vivo calcium imaging with the genetically encoded calcium sensor GCaMP3, we show that TRPV1-expressing trigeminal neurons are activated by heat at behaviorally relevant temperatures. Using knock-down studies, we also show that TRPV1 is required for normal heat-induced locomotion. Our results demonstrate for the first time an ancient role for TRPV1 in the direct sensation of environmental heat and show that heat sensation is adapted to reflect species-dependent requirements in response to environmental stimuli.

\section{Introduction}

The ability to sense environmental temperature is required for survival to maintain homeostasis and to avoid tissue-damaging noxious temperatures. Temperature has been described as the abiotic master factor for aquatic ectotherms such as fish, affecting host range, behavior, and physiology (López-Olmeda and Sánchez-Vázquez, 2011). The genetic determinants for temperature sensation have not been identified in fish, which diverged from tetrapods 360-450 million years ago (Volff, 2005).

It is established that members of the vanilloid family of Transient Receptor Potential (TRP) cation channels, TRPV1-4 are activated by warm to noxious heat in many tetrapod species (Dhaka et al., 2006). In mammals, TRPV1 and TRPV2 could be involved in acute heat sensation because they are expressed in the trigeminal and dor-

Received Nov. 21, 2012; revised Jan. 23, 2013; accepted Feb. 4, 2013.

Author contributions: A.D. designed research; P.G., J.P., C.U.-V., C.D.S., S.G., and A.D. performed research; P.G.,

J.P., C.U.-V., D.W.R., and A.D. analyzed data; P.G., D.W.R., and A.D. wrote the paper.

This work was supported by a Whitehall Foundation Research Grant (A.D.) and National Institutes of Health Grant NS057220 (D.W.R.). P.G. was supported by the National Institute of General Medical Sciences (Molecular and Cell Biology Training Grant GM07270) and the National Institute of Child Health and Human Development (Developmental Biology Training Grant T32HD007183). We thank Sarah Kucenas for providing the $\operatorname{Tg}(p 2 \times 3 b$ :eGFP) fish, Robert Esterberg for providing the Tg(myo6b:GCaMP3) fish, and Andy Prendergast, Corinna Kimball, Mica Rosser, Shamii Goh, and Erinn Wagner for technical assistance.

*P.G. and J.P. contributed equally to this work.

The authors declare no competing financial interests.

Correspondence should be addressed to Ajay Dhaka, Department of Biological Structure, University of Washington, 1959 NE Pacific Street, Box 357420, Seattle, WA 98195. E-mail: dhaka@uw.edu.

DOI:10.1523/JNEUROSCI.5403-12.2013

Copyright $\odot 2013$ the authors $\quad 0270-6474 / 13 / 335249-12 \$ 15.00 / 0$ sal root ganglia (Caterina et al., 1997, 1999). Rodent TRPV1, which is activated at temperatures $>42^{\circ} \mathrm{C}$ and by noxious $\mathrm{pH}$ and capsaicin, is expressed in a subpopulation of small-diameter nociceptive neurons and is required for acute nociception at temperatures $>50^{\circ} \mathrm{C}$ (Caterina et al., 1997, 2000). In contrast, mammalian TRPV2 is activated by very high temperatures $\left(>52^{\circ} \mathrm{C}\right)$ and is expressed in medium- to large-diameter neurons not normally associated with nociception (Caterina et al., 1999). Genetic ablation of mouse TRPV2 has revealed no role for TRPV2 in thermal sensation (Park et al., 2011).

It is not clear when TRPV family members gained/lost the ability to respond to environmentally relevant heat. Unlike other vertebrates studied, zebrafish (Danio rerio) express a single TRPV1/2-like ortholog that, based on the phylogenic analysis, could be derived from an evolutionary precursor of tetrapod TRPV1 and TRPV2 (Saito and Shingai, 2006). Zebrafish embryos respond robustly with increased locomotion to thermal, chemical, and mechanical stimuli that are detected by trigeminal and Rohon-Beard sensory neurons innervating the head and trunk, respectively (Prober et al., 2008). However, receptors for heat sensation have not been identified in zebrafish. One candidate, TRPA1, which is required for heat sensation in Drosophila and potentially for infrared detection in snakes, is necessary for responses to chemical irritants by zebrafish, but is not activated by heat nor necessary for heat sensation (Rosenzweig et al., 2005; Prober et al., 2008; Gracheva et al., 2010).

In the present study, we explore the expression and function of zebrafish TRPV1/2 (referred to hereafter as TRPV1) to understand its role in somatosensation. We provide evidence that ze- 


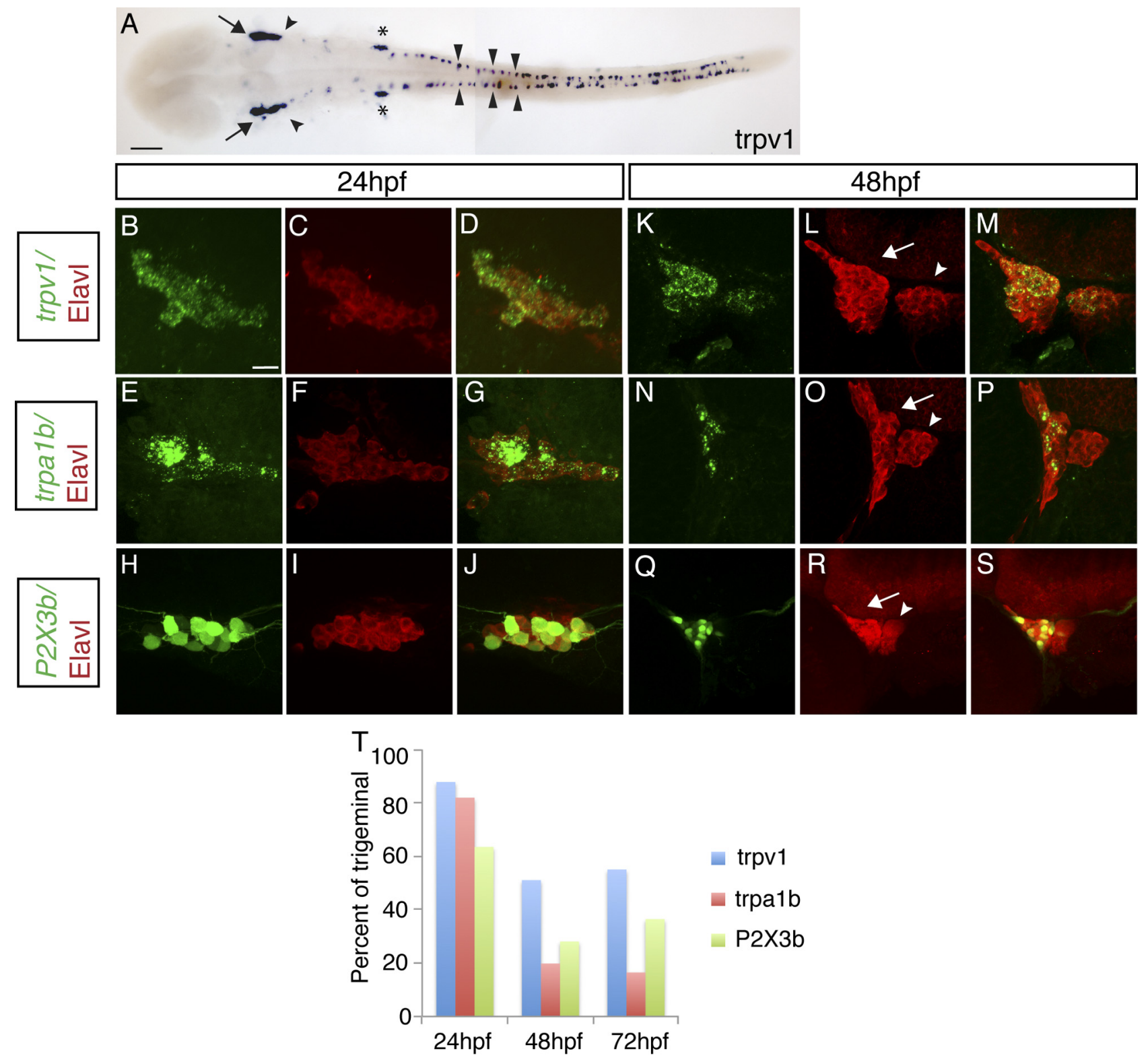

Figure 1. Zebrafish TRPV1 is expressed in different sensory neuron populations. The nociceptive ion channels trpv1, trpa1b, and $p 2 \times 3 b$ label neurons in zebrafish trigeminal ganglion (TG). $A$, In situ hybridization of trpv1 at $24 \mathrm{hpf}$ shows that it is expressed in several sensory structures: the trigeminal (arrow) and anterior lateral line ganglion (arrowhead), the posterior lateral line ganglion $\left({ }^{*}\right)$, and Rohon Beard sensory neurons (flat arrowheads). $\boldsymbol{B}-\boldsymbol{S}$, Antibody staining of Elavl (red) to label the whole trigeminal in conjunction with in situ hybridization of trpv1 (B-D, $\left.\boldsymbol{K}-\boldsymbol{M}\right)$, trpa $1 b$ $(\boldsymbol{E}-\mathbf{G}, \mathbf{N}-\mathbf{P})$, and antibody staining of GFP (H-J, Q-S) in a $\mathrm{Tg}(p 2 \times 3 b$ :eGFP) fish at different time points. Arrow indicates trigeminal; arrowhead, anterior lateral line ganglion. $\boldsymbol{T}, \mathbf{Q u a n t i f i c a t i o n}$ of marker gene expression (\%) in the $\mathrm{TG}$ at 24,48 , and $72 \mathrm{hpf}$. Scale bar, $100 \mu \mathrm{m}$ in $\boldsymbol{A} ; 20 \mu \mathrm{m}$ in $\boldsymbol{B}-\boldsymbol{S}$.

brafish TRPV1 is expressed in nearly all early born trigeminal neurons. A subset of TRPV ${ }^{+}$neurons express TRPA1, reflecting the observed expression pattern of TRPV1 in other vertebrates. We show that environmental hot temperatures activate TRPV1 and TRPV1-expressing neurons. Like other vertebrate TRPV1s, zebrafish TRPV1 is activated by acidic $\mathrm{pH}, 2-\mathrm{APB}$, and PMA, a potent activator of protein kinase C (PKC; Tominaga et al., 1998; Bhave et al., 2003; Hu et al., 2004). Finally, we demonstrate using knock-down studies that TRPV1 is required for normal behavioral responses to heat. These data suggest that TRPV1 has an ancient role in heat sensation dating back 360-450 million years.

\section{Materials and Methods}

\section{Zebrafish husbandry}

Zebrafish were maintained at $28.5^{\circ} \mathrm{C}$ on a $14 \mathrm{~h} / 10 \mathrm{~h}$ light/dark cycle following established methods and institutional animal care and use
Table 1. TG neuron counts identified by Elavl staining

\begin{tabular}{llll}
\hline & $24 \mathrm{hpf}$ & $48 \mathrm{hpf}$ & $72 \mathrm{hpf}$ \\
\hline trpv1 & $22.4 \pm 1.4(10)$ & $32.7 \pm 2.3(7)$ & $37.0 \pm 1.2(3)$ \\
trpa1b & $20.9 \pm 1.6(11)$ & $12.7 \pm 1.4(7)$ & $11.1 \pm 0.3(3)$ \\
P2X3b & $16.2 \pm 2.3(6)$ & $18.0 \pm 0.4(6)$ & $24.5 \pm 3.9(4)$ \\
Elavl & $25.5 \pm 0.9(20)$ & $64.2 \pm 1.4(8)$ & $65.6 \pm 1.5(4)$ \\
\hline
\end{tabular}

Shown are the average number of trpv $1^{+}$, trpa $1 b^{+}{ }^{+}$, or P2X3b ${ }^{+} \mathrm{TG}$ neurons as identified by Elavl staining at 24,48 , and $72 \mathrm{hpf}$. Data are mean \pm SEM (n).

committee standards. Embryos were maintained in E2 medium and staged as described previously (Kimmel et al., 1995). A subset of the trigeminal was identified using $\operatorname{Tg}(p 2 r \times 3 b$ :eGFP $)$, referred to as $p 2 \times 3 b$ : GFP (Kucenas et al., 2006). Hair cells were imaged using $\operatorname{Tg}(m y o 6 b$ : GCaMP3) (kindly provided by R. Esterberg, University of Washington, Seattle, Washington). 

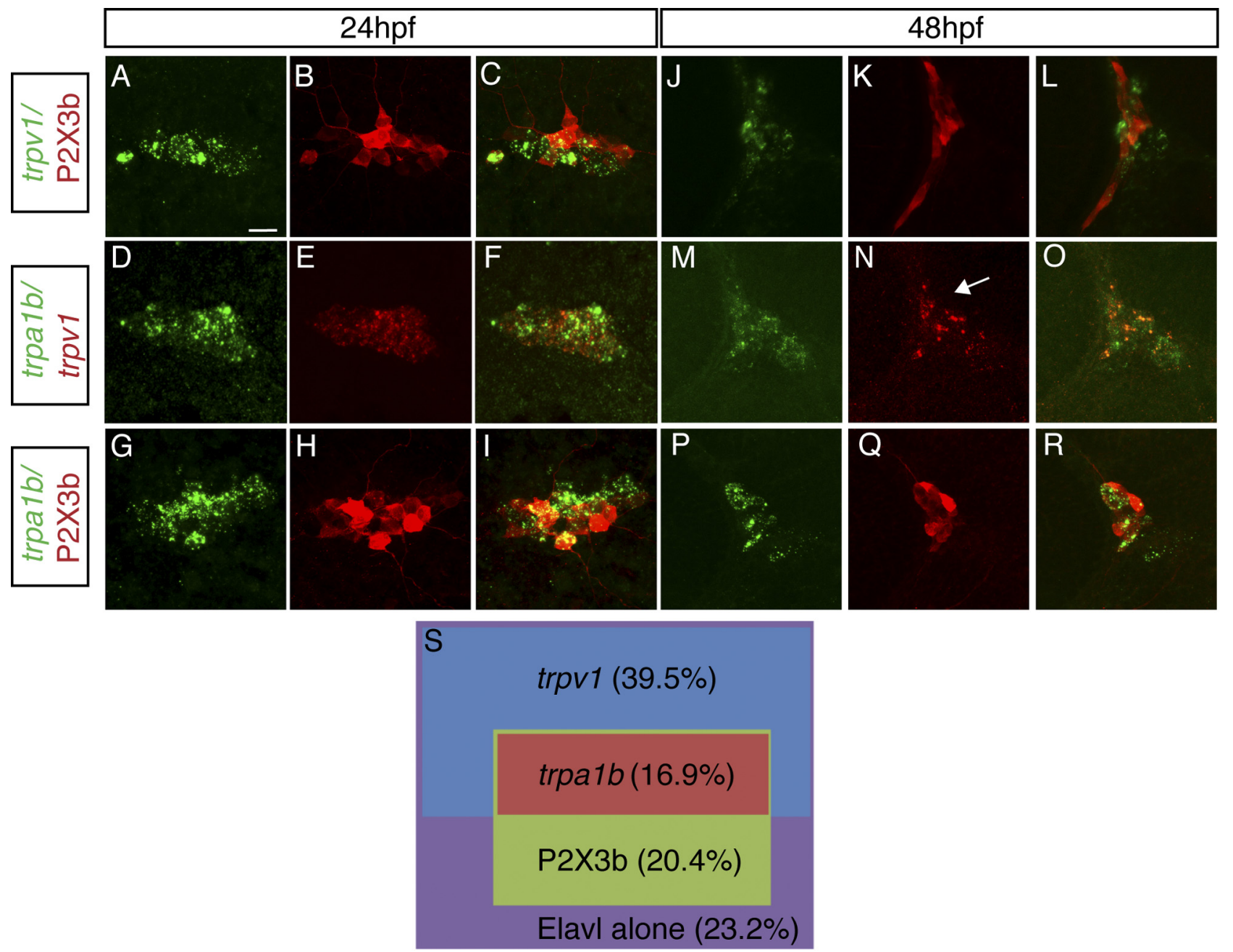

Figure 2. trpv1-expressing neurons in TG form different subpopulations with other nociceptive ion channels. $\boldsymbol{A}-\boldsymbol{R}$, TG where trpv1 and P2X3b-expressing neurons are labeled ( $\boldsymbol{A}-\boldsymbol{C}, \boldsymbol{J}-\boldsymbol{L})$, where trpv1 and trpa $1 b$-expressing neurons are labeled $(\mathbf{G}-\boldsymbol{I}, \boldsymbol{P}-\boldsymbol{R})$, and where trpa $1 b$ and $\mathrm{P} 2 \mathrm{X} 3 \mathrm{~b}$-expressing neurons are labeled. S, Diagram of TG subpopulations at $72 \mathrm{hpf}$. Elavl represents the whole trigeminal. The trpa 16 population is within the P2X3b and trpv1 populations, whereas the P2X3b population does not completely overlap with the trpv1 population. Scale bar, $20 \mu \mathrm{m}$.

\section{DNA constructs}

In situ probe constructs. Zebrafish TRPV1 was cloned from total RNA extracted from 72 hours postfertilization (hpf) zebrafish embryos. trpv1 cDNA was amplified by performing reverse transcription (RT)-PCR with Superscript II (Invitrogen) using primers (F: 5'-GCCGGAATTCATGAGTAAATC-3'; R: 5'-ATTAGTCGACTCAGACGGAGC-3'). The cDNA nucleotide sequence coding for zebrafish TRPV1 consisted of $2439 \mathrm{bp}$ and predicted a protein of 813 amino acid residues. Protein alignment revealed that zebrafish TRPV1/2 is equivalently identical/similar to both rat TRPV1 $(43.8 \% / 58.2 \%)$ and rat TRPV2 (42.6/58\%). trpv1 cDNA was cloned into pBluescript $\mathrm{SK}^{+}$(Stratagene) for in situ hybridization and pIRES-eGFPF (Clontech) for calcium imaging with EcoRI and SalI. trpalb cDNA was digested out of a ztrpal clone (2492848; Exelixis) cloned into pBluescript $\mathrm{SK}^{+}$with XbaI and XhoI.

trpv1:GCaMP3 BAC construction. Bacterial artificial chromosome (BAC) targeting constructs were assembled essentially as described previously (Dhaka et al., 2007). In this approach, a modified BAC-targeting construct (p1452) is used to generate homologous recombinants in BACs containing the gene of interest. Briefly, GCaMP3 was fused in frame to a $150 \mathrm{bp}$ arm upstream of the TRPV1 start codon (upstream arm of homology; uah), and PCR amplified from the BAC clone (CH73-252M19, BACPAC resources) containing the TRPV1 gene using the following primers: 5'-GCAAGGTACCTGTCCCATTTGCTTTTGTGG-3' and 5'ATGATGAGAACCCATTGATTTACTCATAGT-3'. uah-GCaMP3 was then cloned into the BAC-targeting vector (p1452) upstream of an EM7PGK-Neo selection cassette (Tian et al., 2009). A 150 bp fragment of
Table 2. TG neuron counts identified by GFP staining

\begin{tabular}{|c|c|c|c|}
\hline & $24 \mathrm{hpf}$ & $48 \mathrm{hpf}$ & $72 \mathrm{hpf}$ \\
\hline $\operatorname{trpv} 1^{+} P 2 \times 3 b^{-}$ & $7.4 \pm 0.9(9)$ & $25^{a}$ & $21^{a}$ \\
\hline $\operatorname{trpv} 1^{+} P 2 \times 3 b^{+}$ & $10.6 \pm 0.6(9)$ & $7.7 \pm 0.6(7)$ & $16.0 \pm 1.5(3)$ \\
\hline $\operatorname{trpv1}^{-} \mathrm{P}_{2 \times 3 \mathrm{~b}^{+}}$ & $0.1 \pm 0.1(9)$ & $8.0 \pm 0.6(3)$ & $7.0 \pm 0.6(3)$ \\
\hline $\operatorname{trpa1b^{+}} P 2 \times 3 b^{-}$ & $8.3 \pm 0.6(7)$ & $0.3 \pm 0.3(3)$ & $0.3 \pm 0.3(3)$ \\
\hline $\operatorname{trpa1b^{+}} P 2 \times 3 b^{+}$ & $10.9 \pm 0.8(7)$ & $9.5 \pm 1.1(9)$ & $11.8 \pm 0.9(6)$ \\
\hline $\operatorname{trpa1b}{ }^{-} \mathrm{P} 2 \mathrm{X} \mathrm{b}^{+}$ & $0.6 \pm 0.3(7)$ & $8.3 \pm 1.5(3)$ & $8.0 \pm 1.2(4)$ \\
\hline
\end{tabular}

Shown are the average number of different $T G$ subpopulations as identified by GFP staining in $T g(p 2 \times 3 b$ :eGFP) fish. Neurons were double positive for two markers or expressed just one marker. Data are mean \pm SEM $(n)$.

${ }^{a}$ Estimate based on Table 1 and the rest of Table 2. Neurons expressing just trpv 1 were difficult to identify based on in situ hybridization at 48 and $72 \mathrm{hpf}$ because the TG was more complex.

TRPV1 located $170 \mathrm{bp}$ downstream of the uah was amplified using these primers: 5'-GCGCGGATCCGAGACCTCTATTCATTGTTG-3' and 5'GATACCGCGGGTGCACCCTTATGATACG TG-3'. It was then cloned immediately downstream of the selection cassette. The itol2-targeting construct followed a similar cloning strategy. Briefly, an itol2 long terminal repeat was fused to a $150 \mathrm{bp}$ uah in the BAC vector and PCR amplified from the BAC vector using the following primers: $5^{\prime}$-CTAGGGTACCCT GTCAAAACAT- $3^{\prime}$ and 5'-CTCGAGCAGGGTATCTATGTC-3'. uahitol 2 was then cloned into the BAC-targeting vector (p1452) upstream of the selection cassette. A $150 \mathrm{bp}$ dah that was $46 \mathrm{bp}$ downstream of the uah was amplified using these primers: $5^{\prime}$-GAGGATCATAATTAGTAGAC T-3' and 5'-GCATCCGCGGATTAGCGGCCG-3' (Bussmann and 
Schulte-Merker, 2011). It was then cloned immediately downstream of the selection cassette. The GCaMP3 BAC-targeting construct was used to generate homologous recombination in CH73-252M19. Positive clones were floxed to remove the selection cassette. The itol2 BAC-targeting construct was then used to generate homologous recombination in CH73-252M19 containing GCaMP3.

Whole-mount in situ hybridization and antibody staining

trpv1 or trpa1b was subcloned into pBluescript $\mathrm{SK}^{+}$, linearized with NotI, and transcribed with T7 polymerase (Invitrogen) to generate digoxigenin (DIG)-labeled (trpv1) or fluorescein (FLR)-labeled (trpa1b) riboprobe. In situ hybridization was performed as described previously (Thisse and Thisse, 2008). Fluorescent in situ hybridization for trpv1 or trpalb was performed as described previously (Vize et al., 2009). In brief, embryos were hybridized with DIG-labeled or FLR-labeled RNA probes overnight at $55^{\circ} \mathrm{C}$ followed by stringent washes. Samples were incubated with anti-DIG or anti-FLR peroxidaseconjugated Fab fragments (Roche; 1:1000 DIG, 1:500 FLR) and then incubated with Cy3- or FITC-tyramide (PerkinElmer). Embryos were stained with mouse anti-Elavl antibody (Invitrogen; $1: 1000)$ to identify trigeminal sensory neurons and/or rabbit anti-GFP (Invitrogen; 1:1000) to identify a subset of trigeminal sensory neurons in $\operatorname{Tg}(p 2 \times 3 b: e G F P)$ fish, as described previously, and imaged by confocal microscopy (Kucenas et al., 2006). Colocalization of Elavl and trpv1, trpa1b, or GFP in $\operatorname{Tg}(p 2 x 3 b$ :eGFP) fish was analyzed by confocal imaging in single optical planes. Colocalization of GFP and trpv1 or trpa1b in $\operatorname{Tg}(p 2 \times 3 b: e G F P)$ fish was also analyzed by confocal imaging in single optical planes.

\section{Ratiometric calcium imaging}

Calcium imaging was performed essentially as described previously (Dhaka et al., 2009). Human embryonic kidney (HEK) 293T cells were transiently transfected with zebrafish TRPV1-ires-EGFPF or rat TRPV1.pcDNA3 (EGFPf was used as a transfection marker). Transfections were incubated overnight at $37^{\circ} \mathrm{C}$ and then transferred to incubate at $28^{\circ} \mathrm{C}$ to prevent TRPV 1 activation. The buffer solution for all experiments was $1 \times$ Hanks' balanced salt solution (HBSS; Invitrogen) and 10 mM HEPES (Invitrogen), except for studies involving acidic solutions, in which $1 \times$ HBSS was buffered with $10 \mathrm{~mm}$ citric acid-sodium citrate (Sigma) ( $n \geq 80$ cells for all experiments). All averaged traces represent mean \pm SEM. Capsaicin, PMA, Probenecid, and 2-APB were obtained from Sigma.

\section{Electrophysiology}

HEK 293T/17 cells were placed on glass coverslips and transiently transfected with rat-TRPV1.pcDNA3 (EGFP was used as a transfection marker) or zebrafish-TRPV1.pIRES-EGFPF using Lipofectamine 2000 (Invitrogen) according to the manufacturer's instructions. Cells were used for experiments $24-48 \mathrm{~h}$ after transfection. Patch pipettes were made using filamented borosilicate glass and heat polished using a microforge (3.5-4.5 M $\Omega$ ). Depending on the experiment, different patch-clamp configurations were used. For whole-cell experiments, patch pipettes were filled with intracellular saline solution containing the following (in $\mathrm{mm}$ ): $110 \mathrm{~K}$-aspartate, $30 \mathrm{KCl}, 10 \mathrm{NaCl}, 1 \mathrm{MgCl}_{2}, 10$ HEPES, $3 \mathrm{Mg}$-ATP, $0.1 \mathrm{Na}_{3} \mathrm{GTP}$, and 0.05 EGTA, pH 7.2. Cells were perfused with a nominally $\mathrm{Ca}^{2+}$-free extracellular saline solution before the addition of the following stimuli (in $\mathrm{mm}$ ): $140 \mathrm{NaCl}, 4 \mathrm{KCl}, 2$

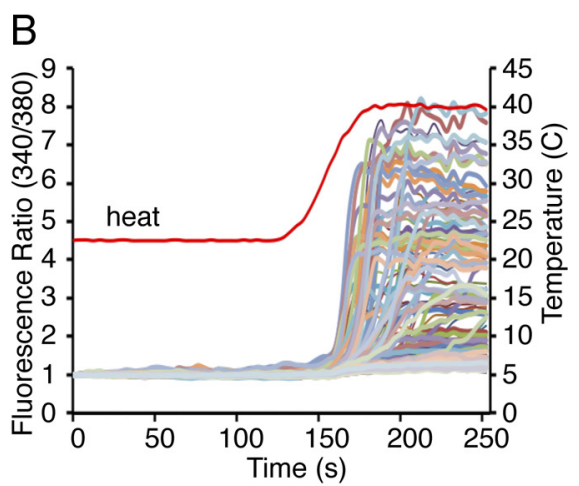

D

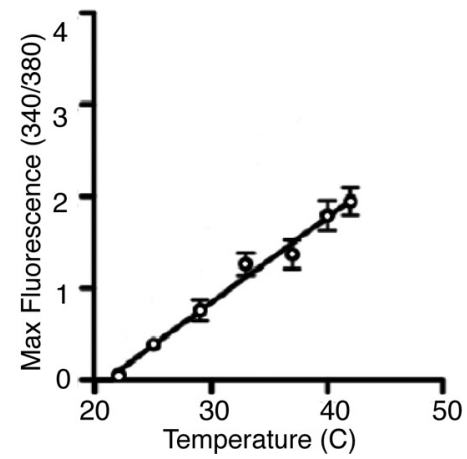

Figure 3. Zebrafish TRPV1 is activated by heat. Responses of zebrafish TRPV1-transfected HEK cells assessed by ratiometric

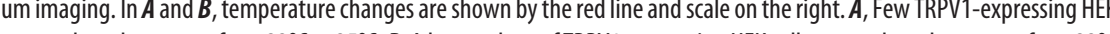
to $40^{\circ} \mathrm{C}$. C, Data from multiple experiments with heat ramps from $22^{\circ} \mathrm{C}$ to $42^{\circ} \mathrm{C}$. The average response of TRPV1-expressing HEK cells increases with exposure to higher temperatures. D, The maximum response of TRPV1-expressing HEK cells increases at higher temperatures. Error bars represent SEM.

$\mathrm{MgCl}_{2}, 10 \mathrm{HEPES}$, and 5 glucose, $\mathrm{pH}$ 7.4. Voltage was clamped at -60 $\mathrm{mV}$. For excised path experiments, patch pipettes were filled with symmetrical recording solution containing the following (in $\mathrm{mm}$ ): $130 \mathrm{NaCl}, 3 \mathrm{HEPES}$, and 0.2 EDTA, pH 7.4. Patches were held at $0 \mathrm{mV}$ and stepped to between -100 and $+100 \mathrm{mV}$ to drive the current. For both types of experiments, solutions were added to cells in a $12 \mathrm{~mm}$ open perfusion chamber using a "sewer pipe" solution changer controlled by the Rapid Solution Changer RSC-200 (Biologic). Currents were recorded using an Axopatch 200B amplifier (Molecular Devices) interfaced to a Dell computer controlled with Pulse (HEKA). For experiments requiring acidic solutions, HEPES was substituted by 2-[N-morpholino] ethanesulfonic acid (MES; pH 5.5, 6.0, and 6.5) or citric acid-sodium citrate ( $\mathrm{pH} 4.5$ and 5.0).

\section{In vivo $\mathrm{Ca}^{2+}$ imaging of trpv1 ${ }^{+}$neurons}

Zebrafish embryos were injected with a trpv1:GCaMP3 BAC $(200 \mathrm{ng} / \mu \mathrm{l})$ with Tol2 transposase $(70 \mathrm{ng} / \mu \mathrm{l})$ to image $\operatorname{trp} v 1^{+}$neurons. At $72 \mathrm{hpf}$, injected embryos were decapitated and the head was embedded in $1 \%$ low-melting-point agarose in a perfusion chamber (Warner Instruments) mounted on an inverted microscope (Olympus) equipped with real-time acquisition and graphing software (MetaFluor; Molecular Devices). Each frame was taken under a $250 \mathrm{~ms}$ exposure at 0.5 frames/s and a region of interest with a trigeminal ganglion (TG) cell body in focus was chosen. Embryo medium was constantly perfused from an 8-line perfusion system. The temperature was adjusted with an in-line heater/cooler (Warner Instruments). To assay chemical responses, embryo medium containing allyl isothiocyanate (AITC or mustard oil; 377430; Sigma) was perfused and diluted to $100 \mu \mathrm{M}$ AITC in 1\% DMSO. Quantitative measures of the intensity of the GCaMP fluorescence from the region of interest were obtained from the photomultiplier data. Changes in fluorescence intensity over time were calculated relative to averaged prestimulus baseline as $\Delta F / F$. 

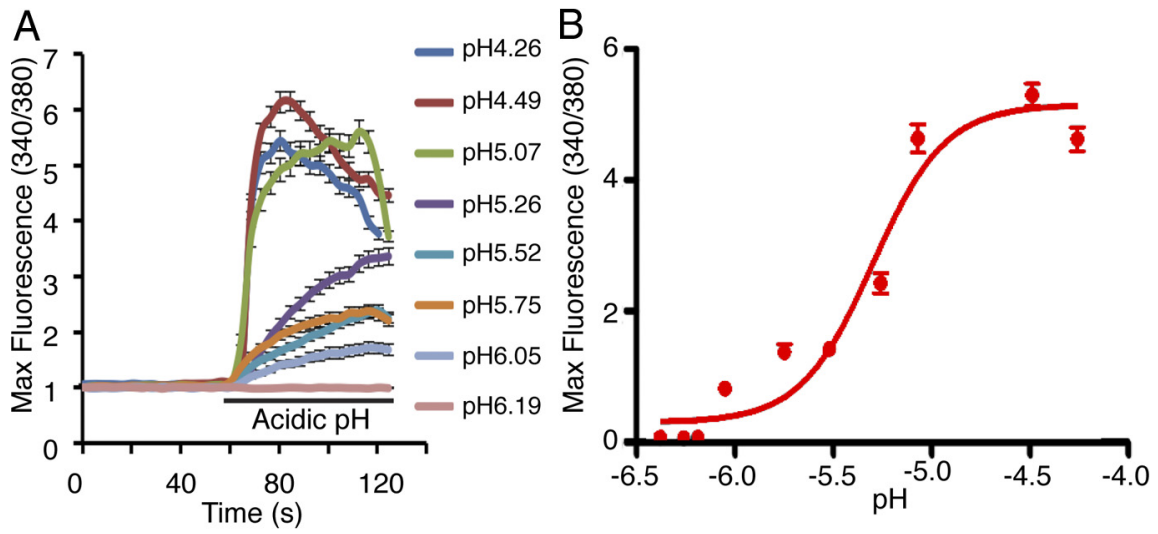

C
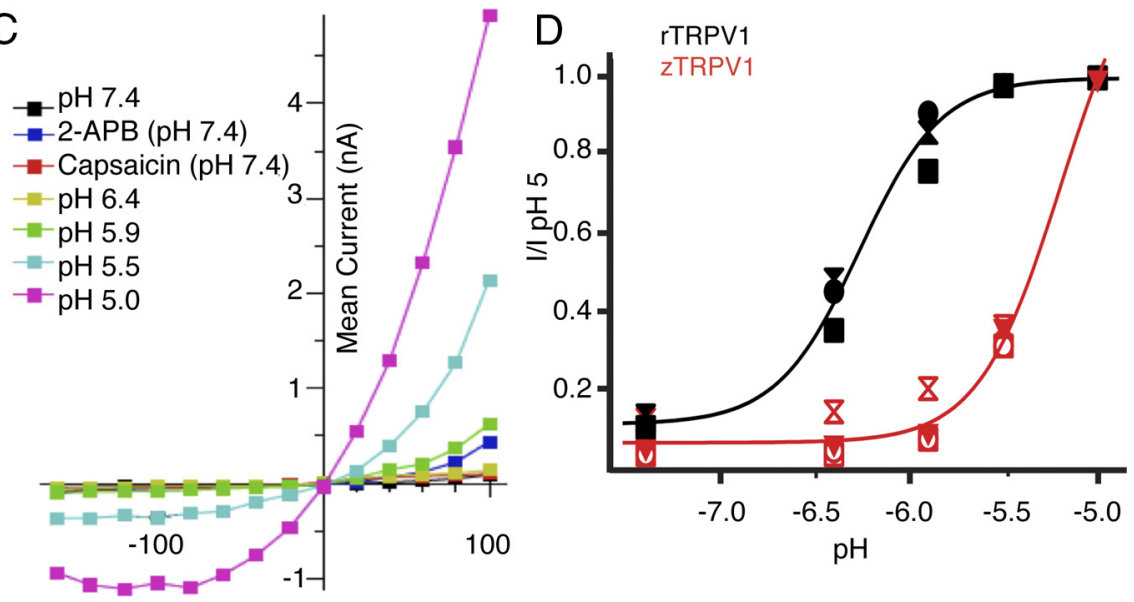

Figure 4. Zebrafish TRPV1 is activated by acidic $\mathrm{pH}$. Responses of zebrafish TRPV1-transfected HEK cells assessed by ratiometric calcium imaging and whole-cell recording. $\boldsymbol{A}$, The average response of TRPV1-expressing HEK cells increases with exposure to more acidic $\mathrm{pH}$. $\boldsymbol{B}$, Dose-response curve of the average maximum response of TRPV1-expressing HEK cells to acidic $\mathrm{pH}$. The threshold is pH 6.0 and the $\mathrm{EC}_{50}$ is $\mathrm{pH}$ 5.3. C, Current-voltage curves of a TRPV1-expressing HEK cell bathed in pH 7.4, followed by 2-APB (200 $\mathrm{nm})$, a TRPV1 agonist, capsaicin (1 $\mu \mathrm{m})$, and increasing acidic $\mathrm{pH}$. $\boldsymbol{D}$, Normalized current evoked by acidic $\mathrm{pH}$ in HEK cells expressing rat or zebrafish TRPV1. Error bars represent SEM.

\section{Behavioral analysis}

Larvae were raised on a $14 \mathrm{~h} / 10 \mathrm{~h}$ light/dark cycle at $28.5^{\circ} \mathrm{C}$. At $72 \mathrm{hpf}$, individual larvae of unknown sex were placed in single wells on a $100 \mu \mathrm{M}$ 96 well mesh plate (MANM 100 10; Millipore). The base plate in which the mesh plate was loaded was constructed from 96 well, $1 \mathrm{~mm}$ Flexwells (RD 475571; Grace Bio-Labs) glued to 0.002-inch aluminum shim in a scrubbed can (ASTM-B-209; ShopAid). The base plates were washed thoroughly and soaked in distilled water before use. Larvae were loaded onto the plate with $120 \mu \mathrm{l}$ of embryo medium into each well using a cut pipette. The mesh plate was placed on one side of a dual solid-state heat/cool plate (AHP-12000CP; Teca) maintained at $23^{\circ} \mathrm{C}$. Water was sprayed on the dual solid-state plate to facilitate temperature transfer. To expose larvae to hot or cold temperatures, the mesh plate was moved to the other side of the dual solid-state plate, which was maintained at different temperatures, and removed at the end of the assay and videotaped for $1 \mathrm{~min}$. To assay chemical responses, the mesh plate was placed in a different base plate, the lid of a 24 multiwell tissue culture plate (353047; BD Labware), containing AITC diluted in 1\% DMSO, and videotaped for $3 \mathrm{~min}$. Behavioral responses were recorded using a Canon high-definition digital video camcorder with a frame rate of 60 frames/s. The locomotor activity of each larva was monitored by the EthoVision XT locomotion tracking software (Noldus Information Technology).

Morpholino oligonucleotide knockdown

A splice-blocking morpholino oligonucleotide (MO) with the sequence GTCACCAAAGCTGCCGTGTAAAAAA was generated based on prediction of efficacy by the manufacturer (Gene Tools). This MO targets the trpv1 intron 13-exon 13 boundary, which encodes part of the pore loop region. Injected embryos were processed for cDNA at $72 \mathrm{hpf}$. Embryos were homogenized in TRIzol reagent (Invitrogen), and total RNA was isolated by column purification (Qiagen). RNA was treated with DNase I (Fermentas) to remove genomic DNA and reverse transcribed (Invitrogen). Primers flanking intron 13 (F: 5'-TGTCTTGCCTTGAGCTGG AT-3', exon 10; R: 5'-GGTCTTTCTCTTCCCC TGAG-3', exon 13) were designed to detect trpv1 transcript.

\section{Results \\ TRPV1 is expressed in a subset of trigeminal neurons}

We investigated the expression of $\operatorname{trp} v 1$ in larval zebrafish using whole-mount in situ hybridization. At $24 \mathrm{hpf}$, trpv1 was exclusively expressed in the somatosensory neurons of the TG, trunk somatosensory Rohon-Beard neurons, and the anterior and posterior lateral line ganglia (Fig. 1A). We used several somatosensory neuron markers to characterize TRPV1 expression at 24,48 , and $72 \mathrm{hpf}$. We labeled different populations using a $p 2 x 3 b$ :GFP BAC-transgenic line that labels a population of nonpeptidergic nociceptive neurons and whole-mount in situ hybridization using probes for trpv1 and trpa1 (0, Kucenas et al., 2006; Kim et al., 2008; Fig. 1B-T, Table 1). Trigeminal somatosensory neurons were identified based on their location and expression of Elavl, a pan-neuronal marker (Prendergast et al., 2012). At $24 \mathrm{hpf}$, we found that trpv1 and $\operatorname{trpa} 1 b$ were in nearly all trigeminal neurons, whereas $p 2 x 3 b$ :GFP was only seen in a subset of neurons (Fig. 1T). By $48 \mathrm{hpf}, \operatorname{trpv1,} \operatorname{trpa1b}$, and $22 \times 3 b$ :GFP were expressed in a smaller proportion of the TG (Fig. $1 T$ ). We also examined how these subpopulations overlapped with the trpv1 population in larval zebrafish (Fig. 2, Table 2). At $24 \mathrm{hpf}$, there was a great deal of overlap among $\operatorname{trp} v 1, \operatorname{trpa} 1 b$, and $p 2 \times 3 b$ :GFP (Fig. $2 A-I$, Fig. $2 S$, Table 2$)$. At $48 \mathrm{hpf}$, the trpalb population was still contained within a $\mathrm{GFP}^{+} / \operatorname{trp} v 1^{+}$population $(97 \%$ of trpalb neurons were $p 2 x 3 b: G F P^{+} ; 100 \%$ of trpal neurons were $\operatorname{trp} v 1^{+}$; Fig. $2 M-R$, Fig. $2 S$, Table 2). In contrast, there was a substantial population of trpv1 neurons that were not $p 2 \times 3 b: G F P^{+}$and $p 2 \times 3 b$ :GFP neurons that were not trpv1 ${ }^{+}$ (67\% of trpv1 neurons were $\mathrm{GFP}^{-}$; $49 \%$ of $p 2 x 3 \mathrm{~b}$ :GFP neurons were $\operatorname{trpv1} 1^{-}$; Table 2). Furthermore, there was an additional population of neurons at $48 \mathrm{hpf}$ that did not express any of these markers (Fig. 2S, Table 1). We found no substantial differences in these expression patterns at $72 \mathrm{hpf}$. These data suggest that by $48 \mathrm{hpf}$, there were at least four different trigeminal sensory neuron subpopulations that could subserve multiple functions.

Zebrafish TRPV1 is activated by agonists of tetrapod TRPV1 Heat has been shown to elicit robust responses in HEK 293T cells transfected with mammalian TRPV1 $\left(\geq 42^{\circ} \mathrm{C}\right)$ or TRPV2 $\left(\geq 52^{\circ} \mathrm{C}\right.$ ), albeit at different thermal thresholds (Caterina et al., $1997,1999)$. Using calcium imaging, we measured the change in 


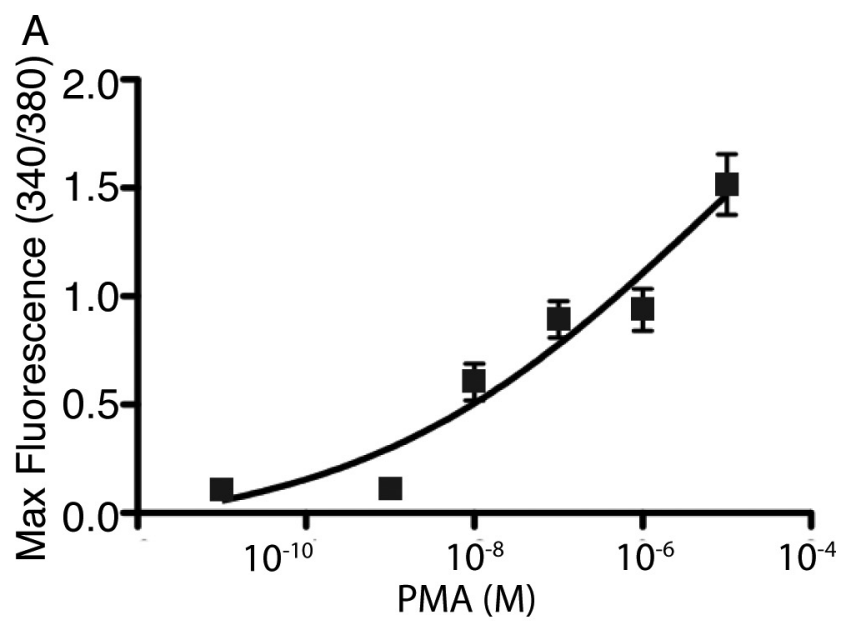

$\mathrm{B}$
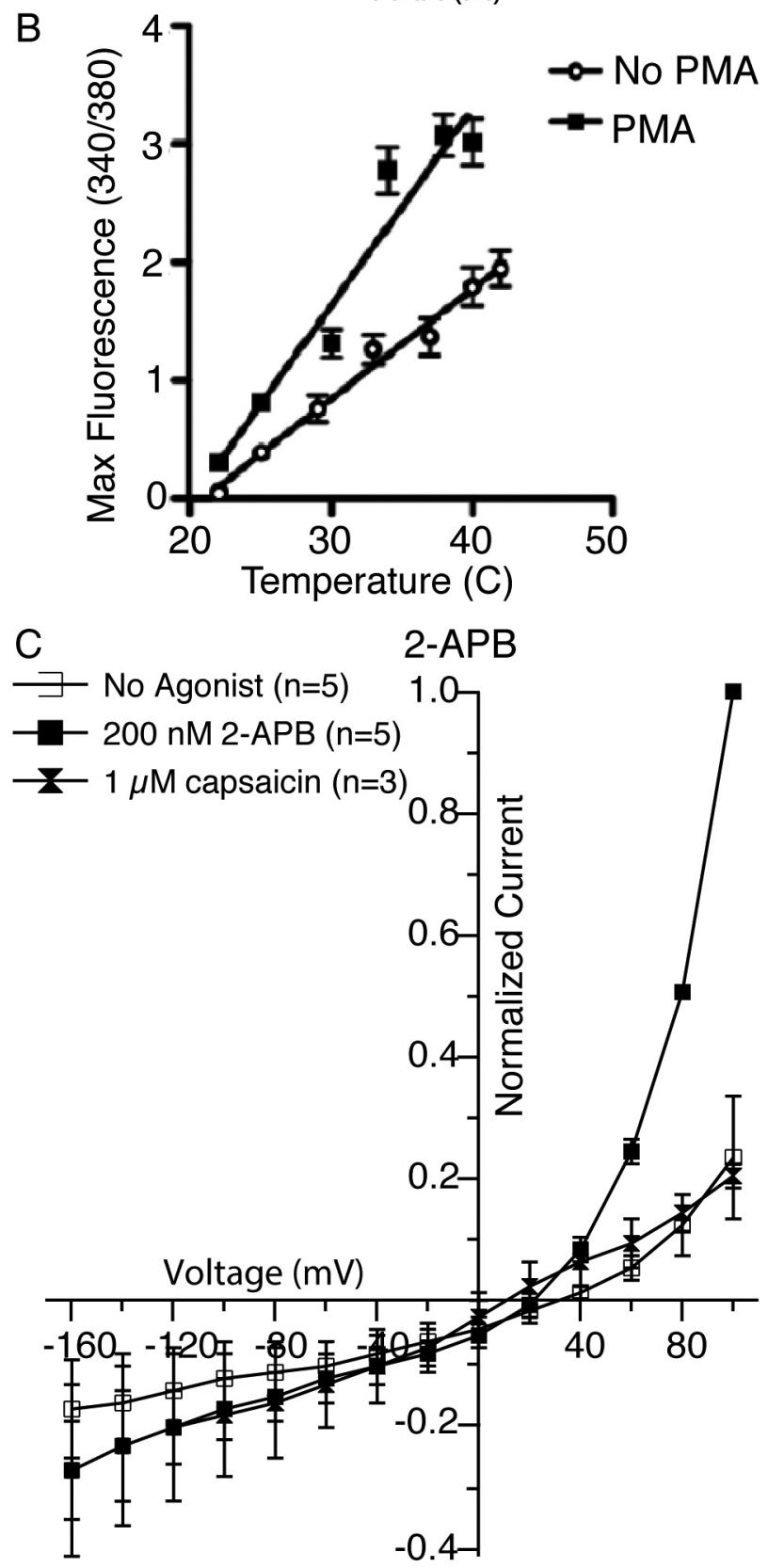

Figure 5. PMA and 2-APB activate zebrafish TRPV1 and potentiate the heat response. Responses of zebrafish TRPV1-transfected HEK cells assessed by ratiometric calcium imaging and patch-clamp recording. $A$, The average response of TRPV1-expressing HEK cells increases to intracellular calcium in HEK cells transfected with zebrafish TRPV1 in response to multiple temperatures starting at $23^{\circ} \mathrm{C}$ and ramping up to temperatures ranging from $25-42^{\circ} \mathrm{C}$. TRPV 1 was activated robustly by increases in temperature. We observed calcium influx in response to relatively minor changes in temperature. Response to application of heat occurred following temperature ramps to $25^{\circ} \mathrm{C}$, with $\sim 30 \%$ of transfected cells responding to the heat stimulus (Fig. $3 A, C$ ). This temperature is below the temperature at which laboratory stocks of zebrafish are normally maintained $\left(28.5^{\circ} \mathrm{C}\right)$ and could be the result of overexpression of the channel in HEK cells. Alternatively, it could be that starting our temperature ramp at room temperature $\left(23^{\circ} \mathrm{C}\right)$ might have altered the channel's sensitivity to heat. Maximal calcium influx was observed at $40^{\circ} \mathrm{C}$, with $\sim 60 \%$ of transfected cells responding (Fig. $3 \mathrm{~B}, \mathrm{C}$ ). We observed no changes in vector- or mock-transfected HEK cells to temperature ramps (data not shown). Additionally, in zebrafish-TRPV1-expressing HEK cells, we did not observe any change in intracellular calcium levels in response to cooling as low as $11^{\circ} \mathrm{C}$ (data not shown). Together with its expression in somatosensory neurons, these data suggest that zebrafish TRPV1 could act as a detector of environmental/ noxious heat in vivo.

Because we observed activation of zebrafish TRPV1 by environmental heat akin to the activation of other vertebrate TRPV1 orthologs, we reasoned that zebrafish TRPV1 might share more properties with TRPV1 orthologs. We therefore investigated whether zebrafish TRPV1 responded to other known activators of mammalian TRPV1 (acidic pH, capsaicin) that have not been shown to activate TRPV2 (Caterina et al., 1997, 1999; Tominaga et al., 1998). Using ratiometric calcium imaging, we found that zebrafish TRPV1 was activated potently by acidic $\mathrm{pH}$. Transfected cells displayed an activation threshold near $\mathrm{pH} 6$ and a half-maximal-effective response near pH 5.2 (Fig. 4A, B). To further characterize acid-induced responses, we recorded TRPV1 channel activity using whole-cell patch-clamp recordings during exposure to acidic $\mathrm{pH}$. We observed rapidly activating and outwardly rectifying currents that were not observed in mockor vector-transfected cells, with an acid response curve that mirrored our findings with calcium imaging (Fig. $4 C, D$ ). Sensitivity to acidic $\mathrm{pH}$ was weaker in zebrafish TRPV1 (median effective concentration, $\mathrm{EC}_{50}, \sim 5.2$ ) compared with rat TRPV1 $\left(\mathrm{EC}_{50}, \sim 6.3\right)$.

Pharmacological interrogation further supports the hypothesis that zebrafish TRPV1 is a functional ortholog of mammalian TRPV1. PMA, a potent PKC activator, has also been shown to activate TRPV1 by stimulating PKC-dependent phosphorylation of TRPV 1 and, potentially, by directly binding and activating the channel (Vellani et al., 2001; Bhave et al., 2003). Activated by several inflammatory mediators, such as ATP, prostaglandins, and bradykinin, PKC is thought to play a role in the sensitization of TRPV1 after inflammation (Huang et al., 2006). PMA application has been shown to potentiate the response of TRPV1 to known TRPV1 ligands such as acid, capsaicin, and heat (Vellani et al., 2001; Bhave et al., 2003). We found that PMA activated zebrafish TRPV1 in a dose-dependent manner at $28^{\circ} \mathrm{C}$ (Fig. $5 A$ ). Furthermore, $1 \mu \mathrm{M}$ PMA, which had minimal effect on zebrafish TRPV1-

increasing concentrations of PMA at $28^{\circ} \mathrm{C}$. B, Perfusing cells with PMA (1 $\left.\mu \mathrm{M}\right)$ increases their response to heat. C, Current-voltage curve of TRPV1 transfected HEK cells exposed to the TRPV1 agonist 2-APB (200 nM), capsaicin $(1 \mu \mathrm{m})$, or vehicle. Currents were normalized to maximum current obtained with 2-APB at $+100 \mathrm{mV}$. Error bars represent SEM. 
A

Human
Mouse
Rat
Rabbit
Dog
Chicken
Rattlesnake
$X$. tropicalis
D. rerio

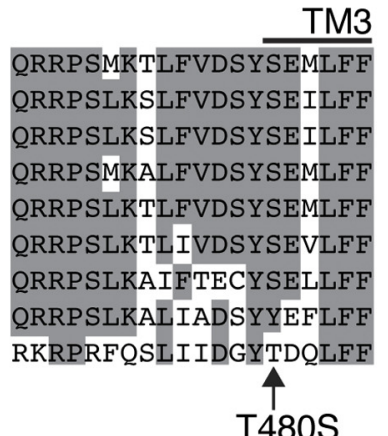

B

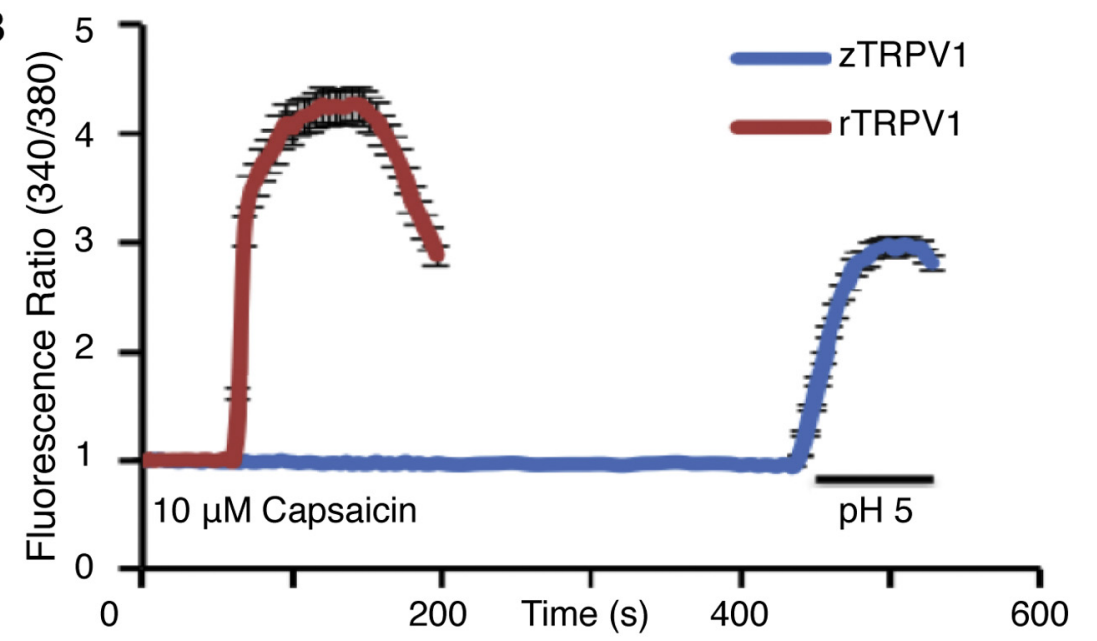

$\mathrm{C}_{\mathbb{0}}$
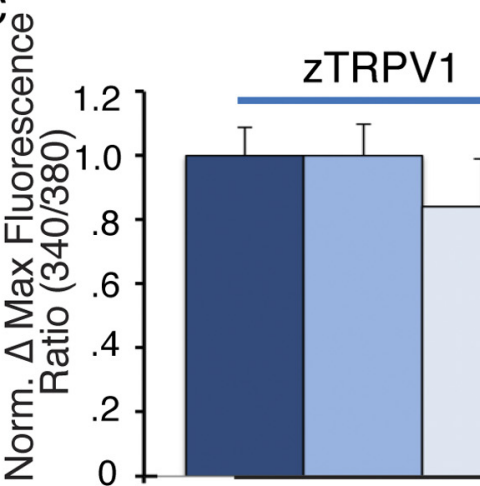

\section{1}
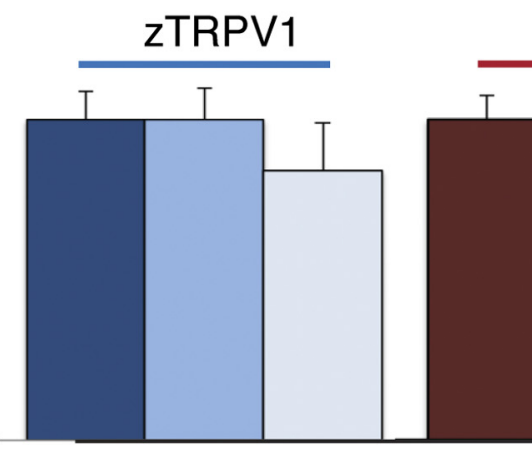

rTRPV1

- $\mathrm{pH} 5$

口PH5+AMG

口 $\mathrm{pH} 5+\mathrm{BCTC}$

$\square \mathrm{pH} 5$

a $\mathrm{pH} 5+\mathrm{AMG}$

$\square \mathrm{pH} 5+\mathrm{BCTC}$

Figure 6. Capsaicin does not activate zebrafish TRPV1. $\boldsymbol{A}$, Amino acid sequence alignments of vertebrate TRPV1s with transmembrane domain 3 (TM3) and TM4. Sites important for capsaicin binding are not conserved in fish. $\boldsymbol{B}$, Responses of zebrafish or rat TRPV1-transfected HEK cells assessed by ratiometric calcium imaging. Zebrafish TRPV1, unlike rat TRPV1, does not respond to capsaicin $(10 \mu \mathrm{M})$, but is responsive to $\mathrm{pH}$ 5. C, The average peak response of TRPV1-transfected HEK cells to $\mathrm{pH} 5$ alone or with TRPV1 antagonists that act at the capsaicin-binding site. These antagonists had no effect on the response of zebrafish TRPV1 to $\mathrm{pH}$, but drastically reduced the response of rat TRPV1 to $\mathrm{pH}$.

transfected cells at $23^{\circ} \mathrm{C}$, potentiated zebrafish TRPV1 activity in response to heat (Fig. 5B). These data show the ability of PMA to enhance zebrafish TRPV1 heat-evoked responses. In addition, 2-APB, which activates TRPV1 and TRPV2 via a vanilloidindependent mechanism(s), also activated zebrafish TRPV1 (Fig. 5C; Hu et al., 2004). Interestingly, zebrafish TRPV1 was not activated by Probenecid, a TRPV2-specific agonist, at concentrations up to $500 \mu \mathrm{M}$ (data not shown).

We also investigated whether the mammalian TRPV1 ligand capsaicin could activate zebrafish TRPV1. Previous studies have shown that capsaicin sensitivity is most potent within mammalian TRPV1 orthologs, and that Xenopus tropicalis, chicken, and rabbit orthologs of TRPV1 are insensitive or weakly activated by capsaicin (Jordt and Julius, 2002; Gavva et al., 2004; Ohkita et al., 2012). Indeed, two residues shown to be required for capsaicin-mediated activation of TRPV1, Ser-512 and Thr-550, were different at the analogous zebrafish positions (Thr-480 and Ile-518, respectively; Fig. 6A; Jordt and Julius, 2002; Gavva et al., 2004). Perhaps unsurprisingly, we observed no activation of zebrafish TRPV1 by capsaicin at concentrations up to 300 $\mu \mathrm{M}$ (Fig. $4 C$, Fig. $6 B$, data not shown). Because many TRPV1 antagonists also act at the capsaicin-binding site, it was unsurprising that the antagonists BCTC and AMG9810 had no effect on acidic-pHinduced activation of zebrafish TRPV1 at concentrations that completely block rat TRPV1 (Fig. 6C; Valenzano et al., 2003; Gavva et al., 2005). Although we cannot completely rule out the possibility that zebrafish TRPV1 shares some TRPV2specific properties, our data indicate that zebrafish TRPV1 is activated by environmental heat, acidic $\mathrm{pH}, \mathrm{PMA}$, and 2-APB, but not by the TRPV2-specific agonist, probenecid, supporting the finding that zebrafish TRPV1 is a functional ortholog of TRPV1 and not TRPV2.

\section{Heat activates trpv1-expressing trigeminal neurons}

To determine whether TRPV1 might function as a heat receptor in vivo, we expressed the genetically encoded calcium indicator GCaMP3 in TRPV1-expressing trigeminal neurons using a trpv1-containing BAC in which GCaMP3 was inserted immediately downstream of the trpv1 start codon. Although our in situ hybridization analysis indicated that TRPV1 was also expressed in both lateral line ganglia, injection of the trpv1:GCaMP3 BAC only yielded embryos expressing GCaMP3 in the trigeminal and Rohon-Beard sensory neurons. We examined heat responses in the TG ganglion because we were able to observe expression in multiple TG neurons routinely after BAC injection. We measured the change in fluorescence of GCaMP3-expressing TG neurons in response to a heat ramp from $23^{\circ} \mathrm{C}$ to a range of temperatures. A $23-27^{\circ} \mathrm{C}$ heat ramp elicited no response in GCaMP3-expressing TG neurons (5/5, 3 larvae). A subset of GCaMP3-expressing TG neurons responded to a $23-28^{\circ} \mathrm{C}$ ramp $(2 / 8,3$ larvae), suggesting that the thermal threshold of TRPV1expressing TG neurons is near $28^{\circ} \mathrm{C}$ (Fig. $\left.7 \mathrm{~B}\right)$. Nearly all neurons responded to heat ramps to $33^{\circ} \mathrm{C}\left(6 / 8,7\right.$ larvae), $36^{\circ} \mathrm{C}(9 / 9,5$ larvae), and $41^{\circ} \mathrm{C}(18 / 19,7$ larvae; Fig. $7 \mathrm{C})$. The average peak amplitude of temperature responses increased with the intensity of the heat ramp, reflecting a graded response by TRPV1expressing TG neurons to increasing heat (Fig. $7 F$ ).

A subset of trpv1:GCaMP3-expressing TG neurons responded to the application of the TRPA1 agonist AITC (3/8, 3 larvae; Fig. 
$7 C, D)$, which supports our expression analysis showing that a subset of TRPV ${ }^{+}$ neurons also expressed TRPA1 (Jordt et al., 2004; Prober et al., 2008). Unexpectedly, when challenged with a $23-11^{\circ} \mathrm{C}$ cold ramp, nearly all trpv1:GCaMP3expressing TG neurons responded (13/14, 4 larvae; Fig. $7 E$ ). However, the average peak amplitude of the cold response was much smaller than that for a heat ramp to $41^{\circ} \mathrm{C}[36.1 \pm 4.4 \Delta F / F(\%), 132.8 \pm 15.1$ $\Delta F / F(\%)$ respectively, $p<0.001]$, indicating that heat is a more potent activator of TRPV1-expressing neurons than cold. The cold response is unlikely to be directly mediated by TRPV1 because it was not activated by cooling when heterologously expressed in HEK293T cells. The fact that TRPV1-expressing neurons respond to both heating and cooling would suggest that these neurons are tuned to detect noxious temperature changes that deviate from normal. To ensure that the changes in fluorescence evoked by heat and cold were not intrinsic properties of the GCaMP3 reporter, we investigated responses to heating and cooling using 72 hpf embryos from a myo6b:GCaMP3 construct in which GCaMP3 is expressed in hair cells. We observed no changes in fluorescence to either heating or cooling, demonstrating that the responses observed after thermal challenge in $\operatorname{trpv1}$ : GCaMP3-expressing TG neurons were due to changes in neuronal activity (data not shown).

\section{Zebrafish show behavioral responses to heat}

Temperature preference has been demonstrated in many fish species, and adult zebrafish have been shown to be able to discriminate between two temperatures. We established an assay to measure thermal discrimination in zebrafish larvae in which $10-15$ larvae were placed in a $55 \times$ $35 \mathrm{~mm}$ aluminum container. In this apparatus, we found that $5 \mathrm{dpf}$ larvae, which have inflated swim bladders, could reproducibly demonstrate thermal preference. When given a choice between $28.5^{\circ} \mathrm{C}$ and noxious cold or hot temperatures, $5 \mathrm{dpf}$ zebrafish larvae consistently avoided the noxious temperature (Fig. 8).

We also developed an assay based on previous studies showing that zebrafish embryos at $72 \mathrm{hpf}$ respond to nociceptive stimuli such as heat, cold, and AITC (Fig. 9, Prober et al., 2008). To measure heat-evoked locomotion, individual embryos in medium $(120 \mu \mathrm{l})$ were placed in a 96 well plate consisting of $10 \times 10$ $\mathrm{mm}$ silicone wells affixed to a $0.05-\mathrm{mm}$-thick sheet of aluminum, and placed on a dual temperature hot/cold plate in which the temperature could be independently controlled on both sides. One side of the plate was set to $23^{\circ} \mathrm{C}$ and the other to the testing temperature. At $23^{\circ} \mathrm{C}$, embryos show little to no locomotor be-

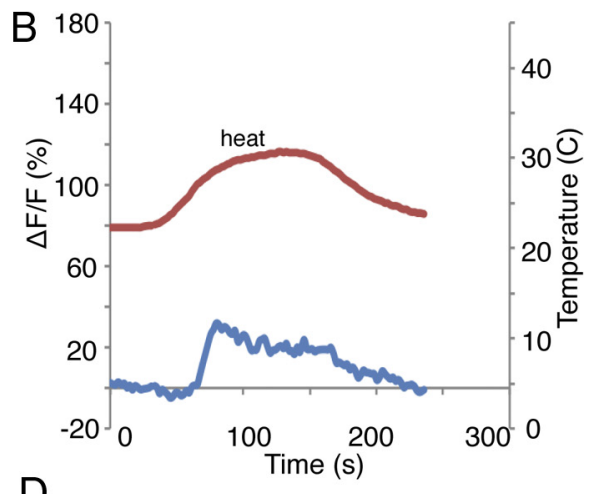

$\mathrm{D}$
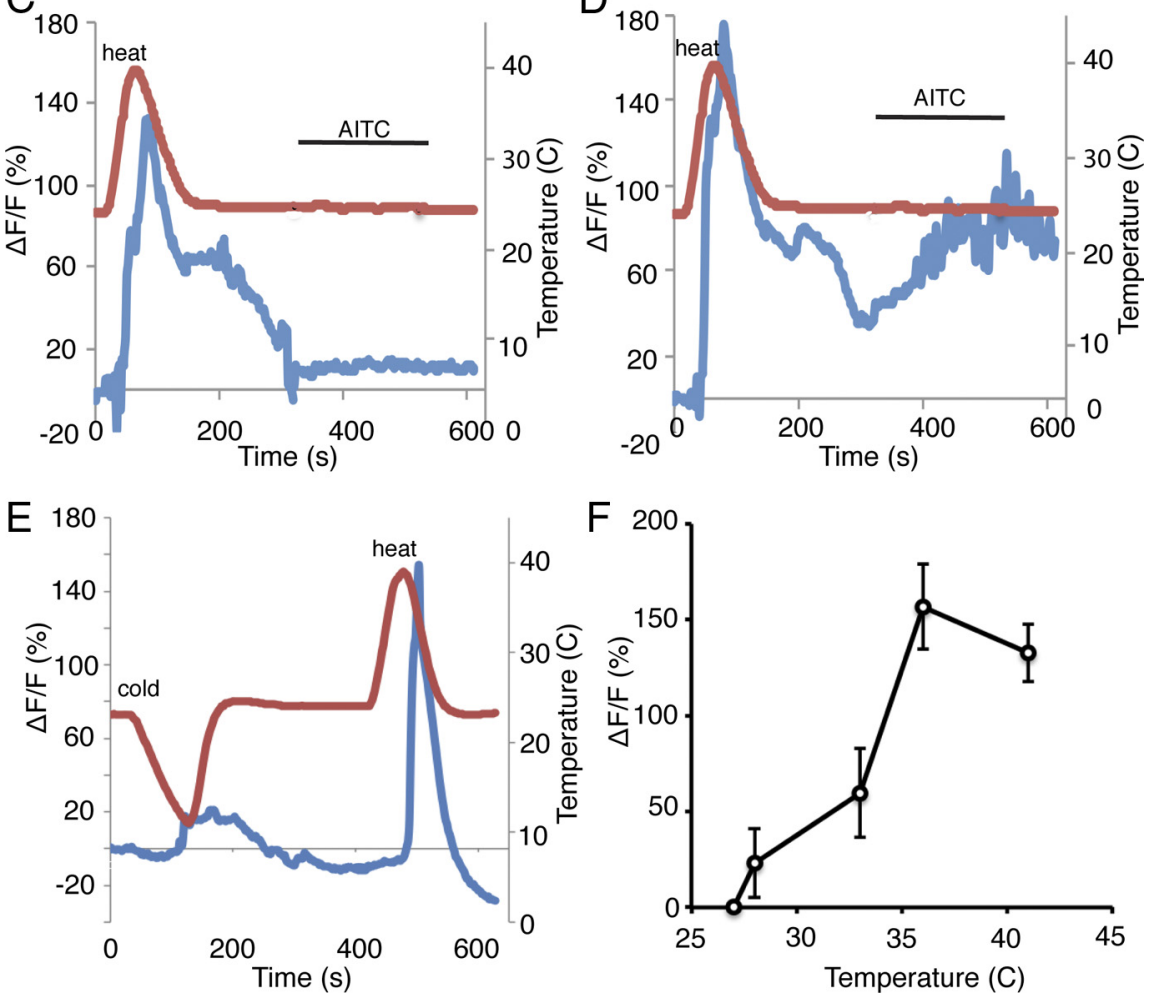

Figure 7. In vivo imaging of trpv1 ${ }^{+}$neurons in response to heat, cold, and AITC. Zebrafish embryos were injected with a trpv1:GCaMP3 BAC. $\boldsymbol{A}$, TG of an injected fish at $72 \mathrm{hpf}$ with $\operatorname{trpv} 1^{+}$neurons labeled by GCaMP3. In $\boldsymbol{B}-\boldsymbol{E}$, temperature changes are shown by the red line and right axis. AITC was added where indicated by the black bar. Blue line indicates normalized change in GCaMP3 intensity. $\boldsymbol{B}$, Representative trace from a heat-responsive neuron to a low heat ramp. $\boldsymbol{C}$, Representative trace from a heat-responsive neuron to a high heat ramp that is not activated by AITC. $D$, A subset of trpv $1^{+}$neurons responds to AITC. responsive neuron that is activated by cold. $\boldsymbol{F}$, Average neuronal response to heat ramps of different intensities. Data are from 5-18 neurons/temperature. Error bars represent SEM.

havior. To measure responses to the testing temperature, the 96 well plate was slid over to the testing temperature and behavior was recorded for $2 \mathrm{~min}$. Locomotor behavior (total distance moved and duration of movement) was measured using tracking software. The water in the wells rapidly $(<10 \mathrm{~s})$ adjusted to the testing temperature due to the low volume and high thermal conductivity of the aluminum bottom. In this assay, $72 \mathrm{hpf} \mathrm{em-}$ bryos showed a heat-dependent increase in locomotion (Fig. 9A). Similarly, 72 hpf embryos respond to cold in a temperaturedependent manner. We found that temperatures $<8^{\circ} \mathrm{C}$ induced movement in $\sim 90 \%$ of wild-type embryos (Fig. $9 B$ ). However, the locomotor movements were minimal, resembling a shivering response, and were not amenable to tracking. We therefore scored responses to cold depending on the presence or absence of 

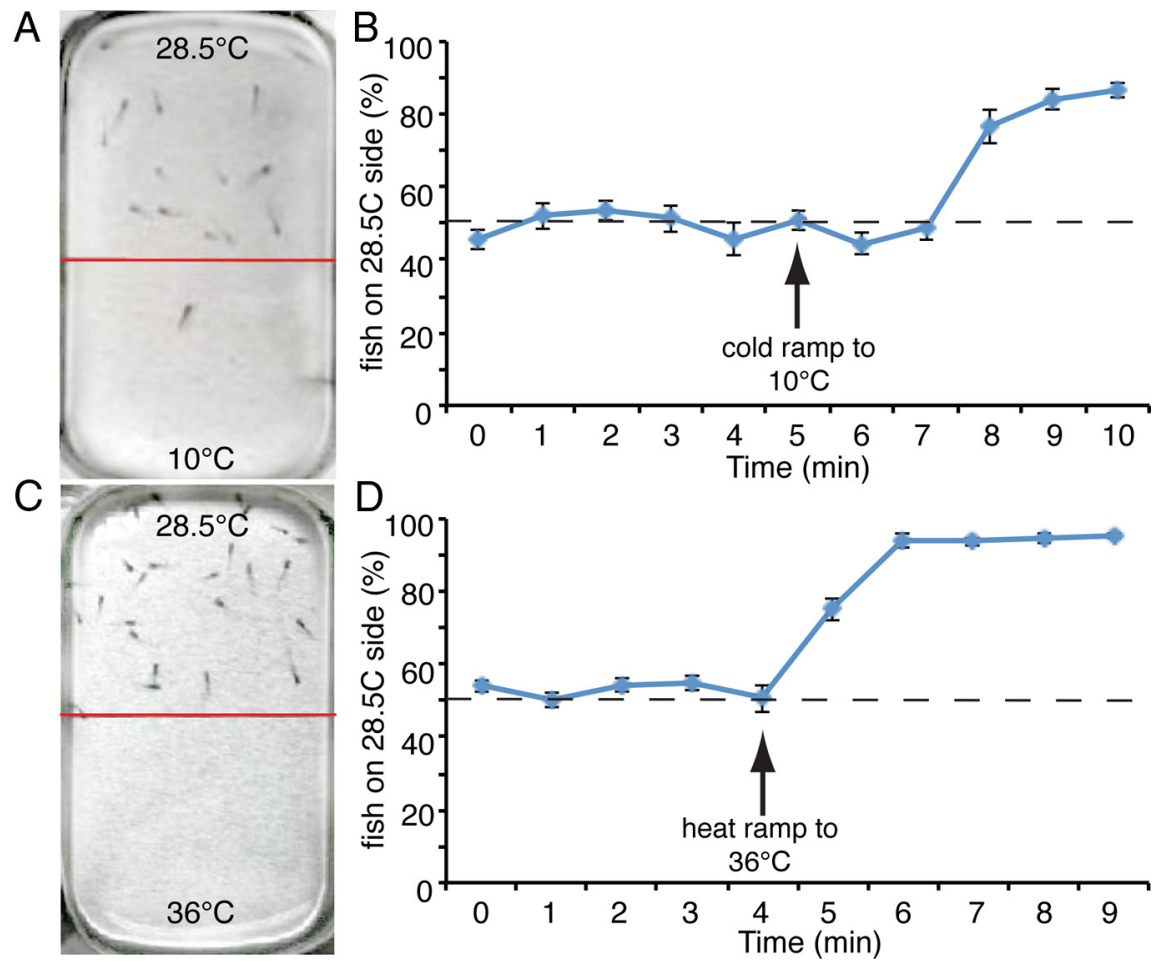

Figure 8. 5 dpf zebrafish robustly avoid noxious hot or cold temperatures. A, B, Zebrafish on a dual solid-state heat/cool plate with one side maintained at $28.5^{\circ} \mathrm{C}$ and one side that is ramped to $10^{\circ} \mathrm{C}$. When both sides are maintained at $28.5^{\circ} \mathrm{C}$, the percent of fish on one side is even. When the temperature on one side is ramped to $10^{\circ} \mathrm{C}$, they actively avoid $10^{\circ} \mathrm{C}$. C, D, Zebrafish on a dual solid-state heat $/ \mathrm{cool}$ plate with one side maintained at $28.5^{\circ} \mathrm{C}$ or ramped to $36^{\circ} \mathrm{C}$. When the temperature on one side is ramped to $36^{\circ} \mathrm{C}$, they actively avoid $36^{\circ} \mathrm{C} . n \geq 5$ trials. Data are from $\sim 15-20$ embryos/trial. Error bars represent SEM.

movement. As we observed for heat, AITC also caused an increase in locomotor escape behavior that was dose dependent and was amenable to tracking (Fig. 9C). Consistent with the inability of capsaicin to activate TRPV1, capsaicin at concentrations up to $300 \mu \mathrm{M}$ (the highest concentration that we could achieve in a $1 \%$ DMSO solution) did not induce any responses in $72 \mathrm{hpf}$ embryos or $5 \mathrm{dpf}$ larvae (data not shown).

\section{TRPV1 is required for acute behavioral responses to heat}

To determine whether TRPV1 plays a role in heat-evoked behavior of zebrafish larvae, we measured heat responses in embryos in which trpv1 expression was knocked down using a MO targeted against the pore loop domain that disrupts trpv1 function by blocking splicing of exon 13 . We began testing at $28.5^{\circ} \mathrm{C}$ because this temperature is near the threshold of TRPV1-expressing TG neurons as assessed by in vivo calcium imaging and is the threshold at which zebrafish begin to respond to heat in our behavioral assay. Embryos injected with 1 or 3 ng of trpv1 MO moved significantly less at $28.5^{\circ} \mathrm{C}$ and $32.5^{\circ} \mathrm{C}$ than control injected larvae while showing no difference in total distance moved at $34.5^{\circ} \mathrm{C}$ (Fig. 10A,B). When incubated in $2.5 \mu \mathrm{M}$ (submaximal dose) or $20 \mu \mathrm{M}$ (maximal dose) AITC, we observed no difference in movement between trpv1 MO or control injected larvae, indicating that the MO was unlikely to have caused off-target nonspecific effects (Fig. 10C). We also found no difference in cold-evoked behavior tested at $6.5^{\circ} \mathrm{C}$ between control and trpv1 MO-injected larvae, further supporting the specificity of the trpv1 MO (Fig. 10D). RT-PCR of trpv1 MO-injected $72 \mathrm{hpf}$ larvae confirmed knockdown of the trpv1 transcript (Fig. 10E). We did not test the effects of the trpv1 MO on $5 \mathrm{dpflarval}$ thermal preference because knockdown of the trpv1 transcript did not last until this time point. Our results support TRPV1 having an acute role in heat sensation in zebrafish larvae.

\section{Discussion}

TRPV1 has been postulated to function as heat sensor in many vertebrate species across a range of innocuous to noxious hot temperatures, and has been shown in mouse knock-out studies to be required for the detection of noxious heat (Caterina et al., 2000; Gracheva et al., 2011; Ohkita et al., 2012). Conversely, TRPV2 has been shown to be only activated by very high temperatures $\left(>52^{\circ} \mathrm{C}\right)$ and is not required for heat sensation (Caterina et al., 1999; Park et al., 2011). Phylogenetic analysis suggests that zebrafish TRPV1, which is equally similar to rat TRPV1 and rat TRPV2, could be derived from an evolutionary precursor that gave rise to tetrapod TRPV1 and TRPV2 via gene duplication (Saito and Shingai, 2006; Saito et al., 2011; Ohkita et al., 2012). In this study, we have shown that the expression, channel properties, and in vivo function of zebrafish TRPV1 mirrors those of tetrapod TRPV1 and not TRPV2, demonstrating that environmental heat and acid sensing are likely ancient properties of the TRPV1/2 precursor. Similar to previous findings, we have shown that zebrafish larvae as young as 72 hpf responded robustly to thermal and chemical stimuli (Prober et al., 2008). We have also developed a high-throughput assay for these behaviors that could be useful in behavior-based genetic screens to discover genes required for nociception or in drug screens to identify potential novel therapeutics.

We hypothesized that if zebrafish TRPV1 is functionally analogous to tetrapod TRPV1, it might share a similar expression pattern. We found that, in agreement with earlier studies, zebrafish TRPV1 is expressed in the somatosensory TG neurons and Rohon-Beard neurons (Caron et al., 2008; Pan et al., 2012). Furthermore, we found that, as in mammals, TRPA1 was expressed in a subset of TRPV1-expressing TG neurons (Story et al., 2003). TRPV 2 expression does not overlap with TRPA1 in rodent somatosensory neurons, demonstrating that zebrafish TRPV1 shares expression traits with TRPV1 and not TRPV2 (Caterina et al., 1999; Tamura et al., 2005). Interestingly, all TG neurons at 24 hpf expressed TRPV1, which is in contrast to chick and rodent development, in which large-diameter proprioceptive and mechanosensitive neurons arise before thermoceptors/nociceptors (Marmigere and Ernfors, 2007). This makes sense because zebrafish develop outside of the mother, so avoiding noxious stimuli would be vital for survival. In addition, TRPV1 expression until at least $72 \mathrm{hpf}$ in a majority of TG neurons might be reflective of mouse TRPV1 expression, where it is initially expressed in a large population of thermoceptor/nociceptor progenitors that is refined into a more specific population over the course of development (Mishra et al., 2011). We also found that at $48 \mathrm{hpf}, \mathrm{P} 2 \mathrm{X} 3 \mathrm{~b}$, a marker of nociceptive neurons in mammals, was expressed in both the TRPV $1^{+} / \mathrm{TRPA1}^{+}$ population and in a $\mathrm{P} 2 \mathrm{X} 3 \mathrm{~b}$-only-expressing population, indicating that even at this early time point there are likely multiple classes of thermoceptors/nociceptors that could code for modality-specific 


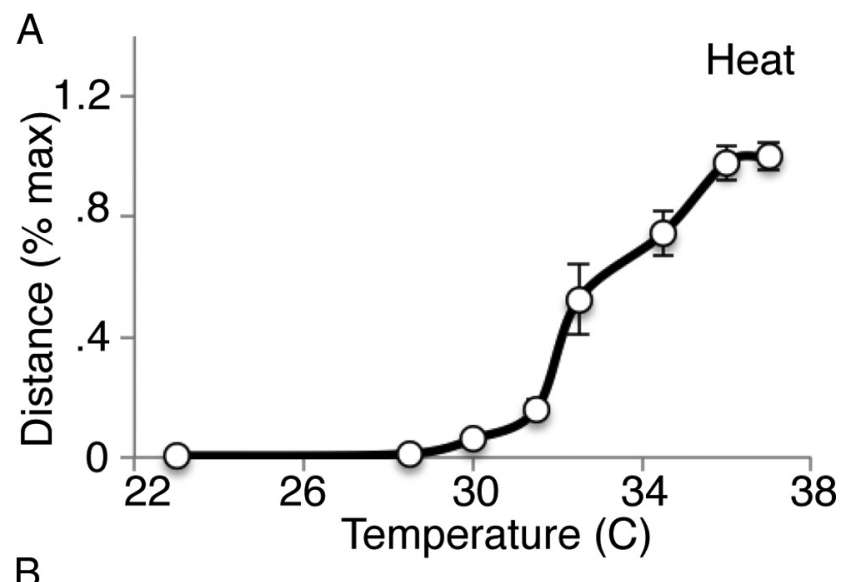

B

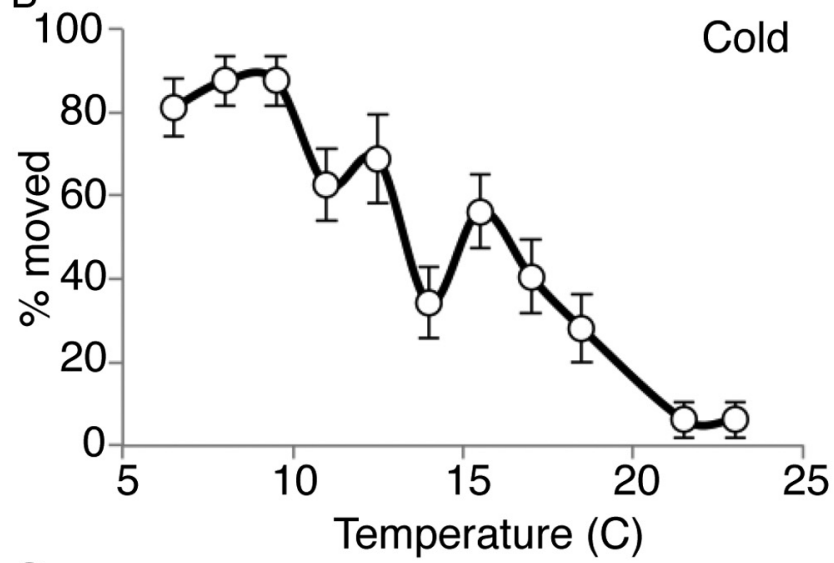

C

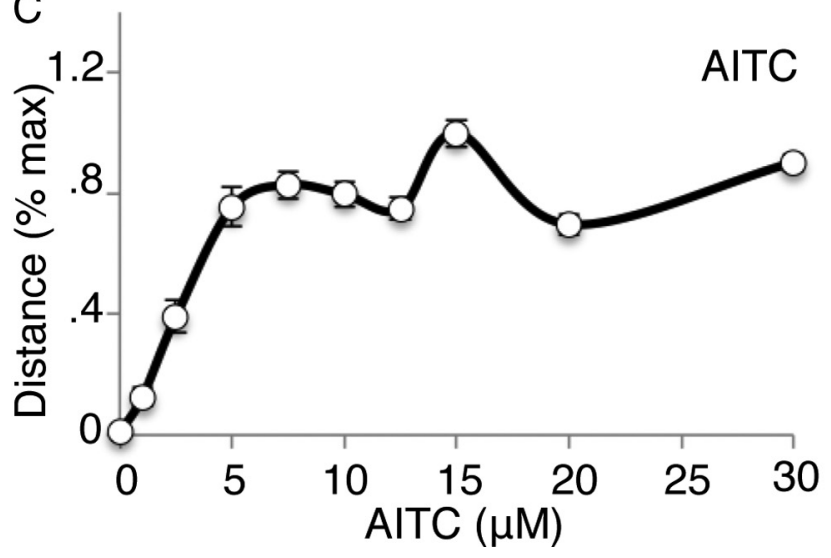

Figure 9. Locomotor responses of 72 hpf zebrafish embryos to heat, cold, and AITC. A, Zebrafish display an increased locomotor response as temperature increases that peaks near $36^{\circ} \mathrm{C}$. B. When exposed to decreasing temperatures, the percentage of $72 \mathrm{hpf}$ embryos that display a locomotor response increase, reaching a peak near $8^{\circ} \mathrm{C}$. C, Locomotor responses to AITC peak near 5-10 $\mu \mathrm{m}$ AITC. $n=32$ embryos for all data points. Error bars represent SEM.

perception (Kim et al., 2008). Unexpectedly, zebrafish TRPV1 was expressed in lateral line ganglion neurons, which receive input from mechanosensory hair cells located in neuromasts along the surface of the head and trunk (Metcalfe et al., 1985; Ghysen and DamblyChaudière, 2007). It is not clear what role TRPV1 may play in these neurons, because they are not thought to have direct sensory properties (Metcalfe et al., 1985; Ghysen and Dambly-Chaudière, 2007).

Heterologously expressed zebrafish TRPV1 was activated by environmentally relevant heat $\left(>25^{\circ} \mathrm{C}\right)$ and was below the threshold of rodent and human TRPV1 activation near $42^{\circ} \mathrm{C}$ (Caterina et al., 1997; Hayes et al., 2000). Peak activity occurred between $37^{\circ} \mathrm{C}$ and $40^{\circ} \mathrm{C}$, which corresponds with the thermal survival limit of zebrafish (near $39^{\circ} \mathrm{C}$ ) and our behavioral studies showing peak heat-induced locomotor activity of zebrafish larvae near $36^{\circ} \mathrm{C}$ (López-Olmeda and Sánchez-Vázquez, 2011). These findings are also in agreement with data showing that the thermal threshold for TRPV1 activation can vary greatly depending on species and splice variant. For example, a splice variant of TRPV1 found in the vampire bat results in a C-terminal truncation and a low thermal threshold $\left(\sim 30^{\circ} \mathrm{C}\right)$ that may confer infrared sensation (Gracheva et al., 2011). Similar to our findings, in the bat study, it appears that heterologously expressed zebrafish TRPV1 started responding to heat at a low temperature $\left(\sim 26^{\circ} \mathrm{C}\right)$. Using an alternative methodology for calculating thermal threshold, they calculated that zebrafish TRPV1 had a thermal threshold $\left(\sim 33^{\circ} \mathrm{C}\right)$ similar to vampire bat TRPV1, and suggested that a contributing factor could be the gap of 12 amino acids within the $\mathrm{C}$ terminus of the zebrafish protein that corresponds to the C-terminal truncation site in vampire bat TRPV1 (Gracheva et al., 2011). The temperature threshold of $X$. tropicalis TRPV1 was also reported to be lower than rodent and human TRPV1, perhaps reflecting the restricted temperature range of $22-28^{\circ} \mathrm{C}$ in that species (Ohkita et al., 2012). Given that the optimal thermal range of different species varies and that the thermal activation threshold of TRPV1 is species dependent suggests that TRPV1 may have evolved to best maintain species-specific behavioral thermal avoidance. In addition, one might postulate that the threshold for heat activation of TRPV1 increased as species evolved from ectotherms to endotherms with relatively high core body temperatures.

To further confirm the identity of zebrafish TRPV1 as an ortholog of tetrapod TRPV1, we found that zebrafish TRPV1 was activated by acidic $\mathrm{pH}$, a specific agonist of TRPV1 and not TRPV2 (Caterina et al., 1997, 1999). However, unlike human and rodent TRPV1, zebrafish TRPV1 was insensitive to capsaicin at concentrations up to $300 \mu \mathrm{M}$ and did not induce a behavioral response in zebrafish larvae. (Caterina et al., 1997; Hayes et al., 2000). Zebrafish TRPV1 is therefore more similar to amphibian, chick, and rabbit TRPV1s, which are insensitive or have very low sensitivity to capsaicin (Jordt and Julius, 2002; Gavva et al., 2004; Ohkita et al., 2012). However, the fact that capsaicin has been reported to activate $X$. tropicalis TRPV1 at high concentrations $\left(\mathrm{EC}_{50}, \sim 85 \mu \mathrm{M}\right)$ and to evoke nocifensive behaviorr in adult $X$. tropicalis would suggest that rudimentary capsaicin sensitivity originated after the gene duplication event that created the independent TRPV1 and TRPV2 lineages from the TRPV1/2 precursor (Ohkita et al., 2012); alternatively, capsaicin sensitivity could have been lost in the zebrafish ortholog. Zebrafish are unlikely to be exposed to capsaicin in their natural environment, obviating any selective pressure to maintain sensitivity. Our data suggest that TRPV2 lost the ability to detect environmental heat and acidic $\mathrm{pH}$ at some time after the gene duplication event that gave rise to TRPV1 and TRPV2 from the TRPV1/2 precursor.

By expressing the genetic calcium indicator GCaMP3 in TRPV1-expressing TG neurons, we observed in vivo that all TRPV $1{ }^{+}$TG neurons were activated by environmentally relevant heat and that a subset was activated by the TRPA1 agonist AITC, which is consistent with our findings that trpal is expressed in a subset of trpv1-expressing neurons. Intriguingly, all TRPV $1{ }^{+} \mathrm{TG}$ neurons were also activated by cold temperature, a clear distinction from rodent TRPV ${ }^{+}$dorsal root ganglion and TG neurons, in which only a fraction of the neurons are cold responsive (Story et al., 2003; Colburn et al., 2007; Dhaka et al., 2007). It would appear that all TRPV1 ${ }^{+}$neurons in larval zebrafish are polymodal temperature sensors. It will be interesting in future studies to determine whether there are populations of zebrafish TG neurons that are singularly heat or cold responders. If not, larval 


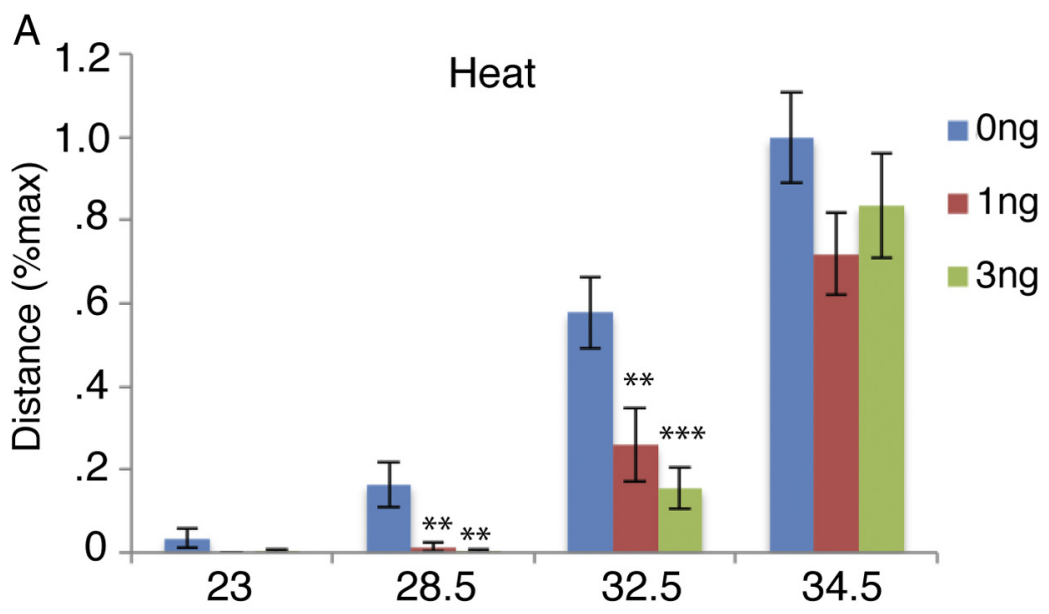

$\mathrm{B}$
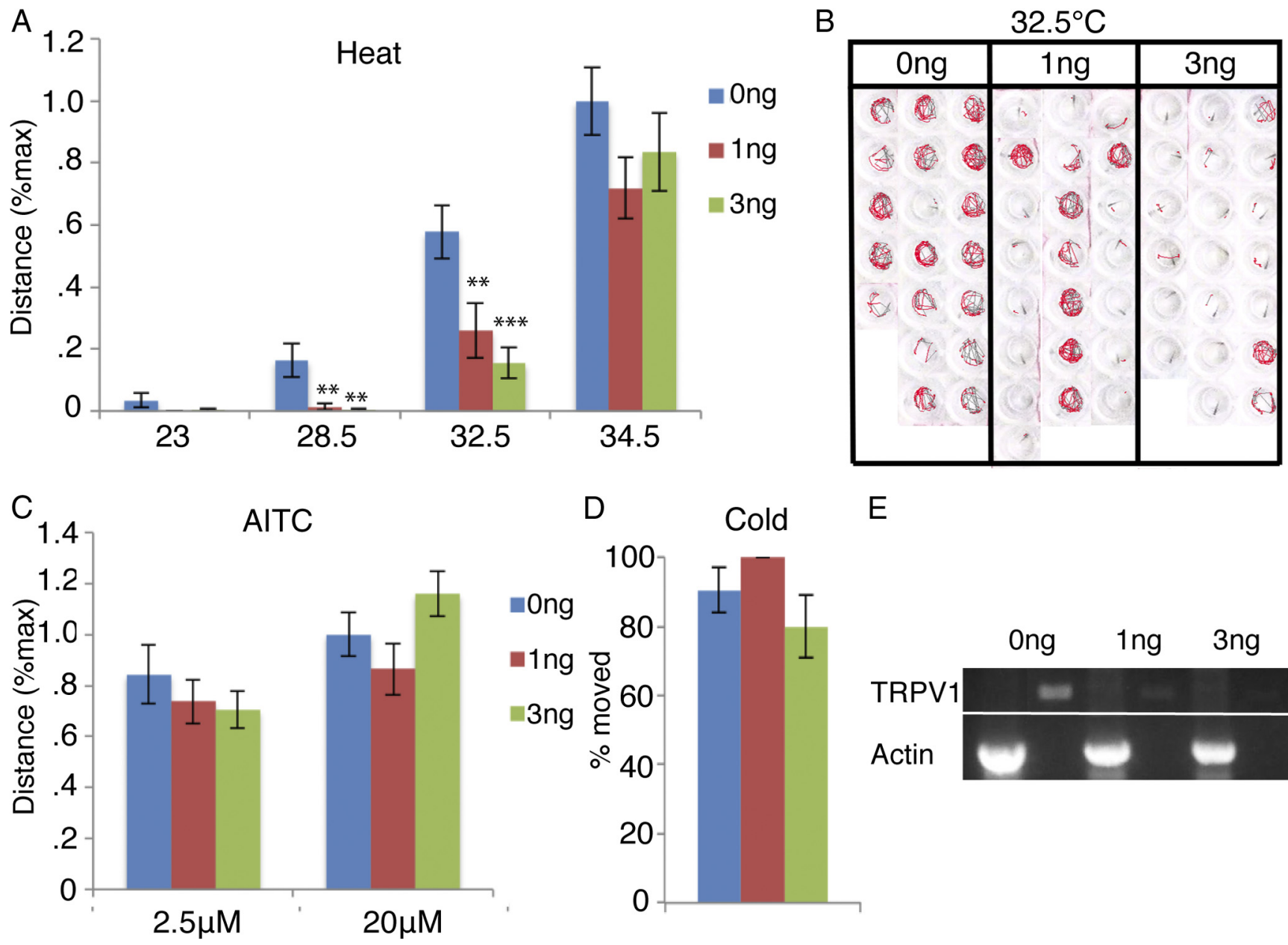

D Cold

$\mathrm{E}$

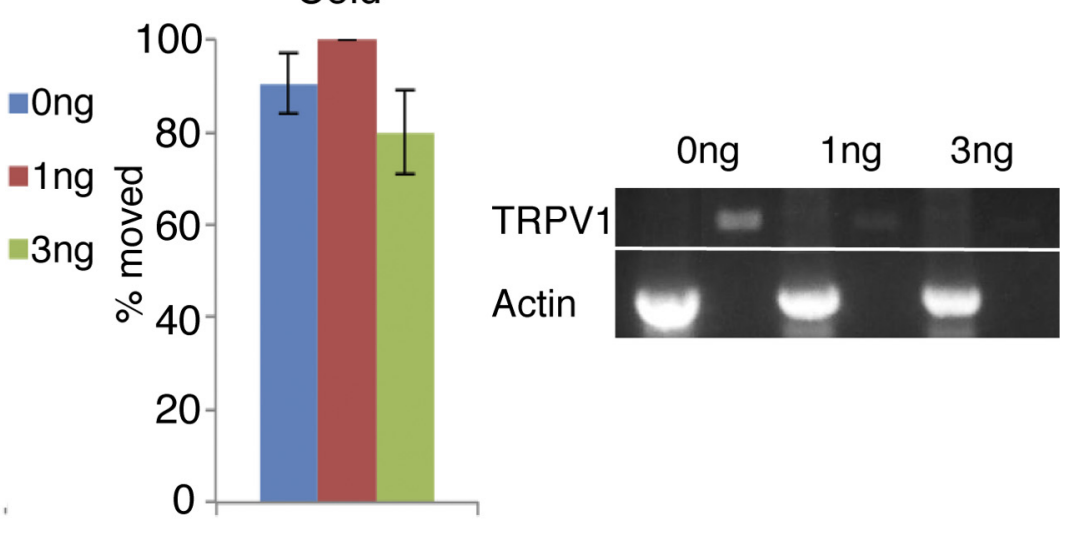

Figure 10. M0 knockdown of trpv1 specifically blocks the heat-induced locomotion at $72 \mathrm{hpf} . \mathrm{A}$, Embryos injected with morpholino showed deficits in heat-induced locomotion at $28.5^{\circ} \mathrm{C}$ and $32.5^{\circ} \mathrm{C}$ in a dose-dependent manner. $\boldsymbol{B}$, Experiment in $\boldsymbol{A}$ visualized by a track plot at $32.5^{\circ} \mathrm{C}$, where the path of the fish is in red. Morpholino injection had no effect on AlTC-induced ( $\left.20 \mu \mathrm{m} ; \boldsymbol{C}\right)$ or cold-induced (D) responses. E, RT-PCR from total RNA extracted from morpholino-injected embryos at $72 \mathrm{hpf}$ shows knockdown of trpv1 in a dose-dependent manner. $n=32 \mathrm{embryos} / \mathrm{condition}$. ${ }^{* *} p<0.01 ;{ }^{* * *} p<0.001$. Error bars represent SEM.

zebrafish may not be able to discriminate between hot and cold, only to detect deleterious changes in temperature.

Finally, we have shown that freely swimming zebrafish larvae as young as $5 \mathrm{dpf}$ robustly avoided hot and cold temperatures and were able to discriminate between noxious and innocuous temperatures. In $72 \mathrm{hpf}$ zebrafish larvae, which cannot swim due to the lack of an inflated swim bladder, rapid heating, cooling, or noxious chemical exposure invokes locomotor escape behavior. Knockdown of trpv1 expression via MO oligonucleotide injection led to a specific inhibition of heat-induced locomotion at temperatures shown to activate TRPV1 in vitro without altering responses to cold and AITC, demonstrating that TRPV1 is required for acute heat sensation at temperatures well within the range that zebrafish larvae would encounter in the wild. However, there was no reduction in heat-induced locomotion at high temperatures. Because we cannot assess the totality of knockdown, we cannot determine whether TRPV1 is entirely responsible for heat-evoked locomotion in zebrafish larvae or if there are other receptors involved in heat sensation, as has been demonstrated in rodents (Vriens et al., 2011; Cho et al., 2012). One intriguing possibility is that TRPV4, which is expressed within forebrain neurons but not peripheral neurons and has a proposed role in heat-induced epileptic seizures, could be responsible for some of the heat-induced behavior (Mangos et al., 2007; Hunt et al., 2012).
Our data support the model that zebrafish TRPV1 is a functional ortholog of tetrapod TRPV1 and suggest an ancient role for the TRPV1/2 precursor in the detection of heat. Our findings add to the growing body of evidence that zebrafish are an effective model system with which to investigate the biology of nociception at the molecular, developmental, physiological, and behavioral levels.

\section{References}

Bhave G, Hu HJ, Glauner KS, Zhu W, Wang H, Brasier DJ, Oxford GS, Gereau RW 4th (2003) Protein kinase C phosphorylation sensitizes but does not activate the capsaicin receptor transient receptor potential vanilloid 1 (TRPV1). Proc Natl Acad Sci U S A 100:12480-12485. CrossRef Medline

Bussmann J, Schulte-Merker S (2011) Rapid BAC selection for tol2mediated transgenesis in zebrafish. Development 138:4327-4332. CrossRef Medline

Caron SJ, Prober D, Choy M, Schier AF (2008) In Vivo Birthdating by BAPTISM Reveals That Trigeminal Sensory Neuron Diversity Depends on Early Neurogenesis. Development 135:3259-3269. CrossRef Medline

Caterina MJ, Schumacher MA, Tominaga M, Rosen TA, Levine JD, Julius D (1997) The capsaicin receptor: a heat-activated ion channel in the pain pathway. Nature 389:816-824. CrossRef Medline

Caterina MJ, Rosen TA, Tominaga M, Brake AJ, Julius D (1999) A capsaicin-receptor homologue with a high threshold for noxious heat. Nature 398:436-441. CrossRef Medline

Caterina MJ, Leffler A, Malmberg AB, Martin WJ, Trafton J, Petersen-Zeitz KR, Koltzenburg M, Basbaum AI, Julius D (2000) Impaired nociception 
and pain sensation in mice lacking the capsaicin receptor. Science 288: 306-313. CrossRef Medline

Cho H, Yang YD, Lee J, Lee B, Kim T, Jang Y, Back SK, Na HS, Harfe BD, Wang F, Raouf R, Wood JN, Oh U (2012) The calcium-activated chloride channel anoctamin 1 acts as a heat sensor in nociceptive neurons. Nat Neurosci 15:1015-1021. CrossRef Medline

Colburn RW, Lubin ML, Stone DJ Jr, Wang Y, Lawrence D, D’Andrea MR, Brandt MR, Liu Y, Flores CM, Qin N (2007) Attenuated cold sensitivity in TRPM8 null mice. Neuron 54:379-386. CrossRef Medline

Dhaka A, Viswanath V, Patapoutian A (2006) Trp ion channels and temperature sensation. Ann Rev Neurosci 29:135-161. CrossRef Medline

Dhaka A, Murray AN, Mathur J, Earley TJ, Petrus MJ, Patapoutian A (2007) TRPM8 is required for cold sensation in mice. Neuron 54:371-378. CrossRef Medline

Dhaka A, Uzzell V, Dubin AE, Mathur J, Petrus M, Bandell M, Patapoutian A (2009) TRPV1 is activated by both acidic and basic pH. J Neurosci 29: 153-158. CrossRef Medline

Gavva NR, Klionsky L, Qu Y, Shi L, Tamir R, Edenson S, Zhang TJ, Viswanadhan VN, Toth A, Pearce LV, Vanderah TW, Porreca F, Blumberg PM, Lile J, Sun Y, Wild K, Louis JC, Treanor JJ (2004) Molecular Determinants of Vanilloid Sensitivity in TRPV1. J Biol Chem 279:20283-20295. CrossRef Medline

Gavva NR, Tamir R, Qu Y, Klionsky L, Zhang TJ, Immke D, Wang J, Zhu D, Vanderah TW, Porreca F, Doherty EM, Norman MH, Wild KD, Bannon AW, Louis JC, Treanor JJ (2005) AMG 9810 [(E)-3-(4-t-butylphenyl)- $N$ (2,3-dihydrobenzo[1,4] dioxin-6-yl)acrylamide], a novel vanilloid receptor 1 (TRPV1) antagonist with antihyperalgesic properties. J Pharmacol Exp Ther 313:474-484. CrossRef Medline

Ghysen A, Dambly-Chaudière C (2007) The lateral line microcosmos. Genes Dev 21:2118-2130. CrossRef Medline

Gracheva EO, Ingolia NT, Kelly YM, Cordero-Morales JF, Hollopeter G, Chesler AT, Sánchez EE, Perez JC, Weissman JS, Julius D (2010) Molecular basis of infrared detection by snakes. Nature 464:1006-1011. CrossRef Medline

Gracheva EO, Cordero-Morales JF, González-Carcacía JA, Ingolia NT, Manno C, Aranguren CI, Weissman JS, Julius D (2011) Ganglionspecific splicing of TRPV1 underlies infrared sensation in vampire bats. Nature 476:88-91. CrossRef Medline

Hayes P, Meadows HJ, Gunthorpe MJ, Harries MH, Duckworth DM, Cairns W, Harrison DC, Clarke CE, Ellington K, Prinjha RK, Barton AJ, Medhurst AD, Smith GD, Topp S, Murdock P, Sanger GJ, Terrett J, Jenkins O, Benham CD, Randall AD, Gloger IS, Davis JB (2000) Cloning and functional expression of a human orthologue of rat vanilloid receptor-1. Pain 88:205-215. CrossRef Medline

Huang J, Zhang X, McNaughton PA (2006) Modulation of temperaturesensitive TRP channels. Seminars in Cell and Developmental Biology 17:638-645. CrossRef Medline

Hunt RF, Hortopan GA, Gillespie A, Baraban SC (2012) A novel zebrafish model of hyperthermia-induced seizures reveals a role for TRPV4 channels and NMDA-type glutamate receptors. Exp Neurol 237:199-206. CrossRef Medline

Hu HZ, Gu Q, Wang C, Colton CK, Tang J, Kinoshita-Kawada M, Lee LY, Wood JD, Zhu MX (2004) 2-Aminoethoxydiphenyl borate is a common activator of TRPV1, TRPV2, and TRPV3. J Biol Chem.

Jordt SE, Julius D (2002) Molecular basis for species-specific sensitivity to "hot" chili peppers. Cell 108:421-430. CrossRef Medline

Jordt SE, Bautista DM, Chuang HH, McKemy DD, Zygmunt PM, Hogestatt ED, Högestätt ED,Meng ID, Julius D (2004) Mustard oils and cannabinoids excite sensory nerve fibres through the TRP channel ANKTM1. Nature 427:260-265. CrossRef Medline

Kim YS, Paik SK, Cho YS, Shin HS, Bae JY, Moritani M, Yoshida A, Ahn DK, Valtschanoff J, Hwang SJ, Moon C, Bae YC (2008) Expression of P2X3 receptor in the trigeminal sensory nuclei of the rat. J Comp Neurol 506: 627-639. CrossRef Medline

Kimmel CB, Ballard WW, Kimmel SR, Ullmann B, Schilling TF (1995) Stages of embryonic development of the zebrafish. Developmental Dynamics 203:253-310. CrossRef Medline

Kucenas S, Soto F, Cox JA, Voigt MM (2006) Selective labeling of central and peripheral sensory neurons in the developing zebrafish using P2X3 receptor subunit transgenes. Neuroscience 138:641-652. CrossRef Medline
López-Olmeda JF, Sánchez-Vázquez FJ (2011) Thermal biology of zebrafish (Danio rerio). J Therm Biol 36:91-104. CrossRef

Mangos S, Liu Y, Drummond IA (2007) Dynamic expression of the osmosensory channel trpv4 in multiple developing organs in zebrafish. Gene Expression Patterns 7:480-484. CrossRef Medline

Marmigère F, Ernfors P (2007) Specification and connectivity of neuronal subtypes in the sensory lineage. Nat Rev Neurosci 8:114-127. CrossRef Medline

Metcalfe WK, Kimmel CB, Schabtach E (1985) Anatomy of the posterior lateral line system in young larvae of the zebrafish. J Comp Neurol 233: 377-389. CrossRef Medline

Mishra SK, Tisel SM, Orestes P, Bhangoo SK, Hoon MA (2011) TRPV1lineage neurons are required for thermal sensation. EMBO J 30:582-593. CrossRef Medline

Ohkita M, Saito S, Imagawa T, Takahashi K, Tominaga M, Ohta T (2012) Molecular cloning and functional characterization of Xenopus tropicalis frog transient receptor potential vanilloid 1 reveal its functional evolution for heat, acid, and capsaicin sensitivities in terrestrial vertebrates. J Biol Chem 287:2388-2397. CrossRef Medline

Pan YA, Choy M, Prober DA, Schier AF (2012) Robo2 determines subtypespecific axonal projections of trigeminal sensory neurons. Development 139:591-600. CrossRef Medline

Park U, Vastani N, Guan Y, Raja SN, Koltzenburg M, Caterina MJ (2011) TRP vanilloid 2 knock-out mice are susceptible to perinatal lethality but display normal thermal and mechanical nociception. J Neurosci 31: 11425-11436. CrossRef Medline

Prendergast A, Linbo TH, Swarts T, Ungos JM, McGraw HF, Krispin S, Weinstein BM, Raible DW (2012) The metalloproteinase inhibitor Reck is essential for zebrafish DRG development. Development 139:1141-1152. CrossRef Medline

Prober DA, Zimmerman S, Myers BR, McDermott BM Jr, Kim SH, Caron S, Rihel J, Solnica-Krezel L, Julius D, Hudspeth AJ, Schier AF (2008) Zebrafish TRPA1 channels are required for chemosensation but not for thermosensation or mechanosensory hair cell function. J Neurosci 28 : 10102-10110. CrossRef Medline

Rosenzweig M, Brennan KM, Tayler TD, Phelps PO, Patapoutian A, Garrity PA (2005) The Drosophila ortholog of vertebrate TRPA1 regulates thermotaxis. Genes Dev 19:419-424. CrossRef Medline

Saito S, Shingai R (2006) Evolution of thermoTRP ion channel homologs in vertebrates. Physiol Genomics 27:219-230. CrossRef Medline

Saito S, Fukuta N, Shingai R, Tominaga M. (2011) Evolution of vertebrate transient receptor potential vanilloid 3 channels: opposite temperature sensitivity between mammals and western clawed frogs. PLoS Genet 7:e1002041. CrossRef Medline

Story GM, Peier AM, Reeve AJ, Eid SR, Mosbacher J, Hricik TR, Earley TJ, Hergarden AC, Andersson DA, Hwang SW, McIntyre P, Jegla T, Bevan S, Patapoutian A (2003) ANKTM1, a TRP-like channel expressed in nociceptive neurons, is activated by cold temperatures. Cell 112:819-829. CrossRef Medline

Tamura S, Morikawa Y, Senba E (2005) TRPV2, a capsaicin receptor homologue, is expressed predominantly in the neurotrophin-3-dependent subpopulation of primary sensory neurons. Neuroscience 130:223-228. CrossRef Medline

Thisse C, Thisse B (2008) High-resolution in situ hybridization to wholemount zebrafish embryos. Nat Protoc 3:59-69. CrossRef Medline

Tian L, Hires SA, Mao T, Huber D, Chiappe ME, Chalasani SH, Petreanu L, Akerboom J, McKinney SA, Schreiter ER, Bargmann CI, Jayaraman V, Svoboda K, Looger LL (2009) Imaging neural activity in worms, flies and mice with improved GCaMP calcium indicators. Nat Methods 6:875881. CrossRef Medline

Tominaga M, Caterina MJ, Malmberg AB, Rosen TA, Gilbert H, Skinner K, Raumann BE, Basbaum AI, Julius D (1998) The cloned capsaicin receptor integrates multiple pain-producing stimuli. Neuron 21:531-543. CrossRef Medline

Valenzano KJ, Grant ER, Wu G, Hachicha M, Schmid L, Tafesse L, Sun Q, Rotshteyn Y, Francis J, Limberis J, Malik S, Whittemore ER, Hodges D (2003) $\mathrm{N}$-(4-tertiarybutylphenyl)-4-(3-chloropyridin-2-yl)tetrahydropyrazine$1(2 \mathrm{H})$-carbox-amide (BCTC), a novel, orally effective vanilloid receptor 1 antagonist with analgesic properties: I. in vitro characterization and pharmacokinetic properties. J Pharmacol Exp Ther 306:377-386. CrossRef Medline

Vellani V, Mapplebeck S, Moriondo A, Davis JB, McNaughton PA (2001) Protein kinase $\mathrm{C}$ activation potentiates gating of the vanilloid receptor 
VR1 by capsaicin, protons, heat and anandamide. J Physiol 534:813-825. CrossRef Medline

Vize PD, McCoy KE, Zhou X (2009) Multichannel wholemount fluorescent and fluorescent/chromogenic in situ hybridization in Xenopus embryos. Nat Protoc 4:975-983. CrossRef Medline

Volff JN (2005) Genome evolution and biodiversity in teleost fish. Heredity 94:280-294. CrossRef Medline
Vriens J, Owsianik G, Hofmann T, Philipp SE, Stab J, Chen X, Benoit M, Xue F, Janssens A, Kerselaers S, Oberwinkler J, Vennekens R, Gudermann T, Nilius B, Voets T (2011) TRPM3 Is a Nociceptor Channel Involved in the Detection of Noxious Heat. Neuron 70:482-494. CrossRef Medline 